\title{
A CYC-RAD-DIV-DRIF interaction likely pre-dates the origin of floral monosymmetry in Lamiales
}

\author{
Aniket Sengupta ${ }^{1,2^{*}}$ (1) and Lena C. Hileman ${ }^{1}$
}

\begin{abstract}
Background: An outstanding question in evolutionary biology is how genetic interactions defining novel traits evolve. They may evolve either by de novo assembly of previously non-interacting genes or by en bloc co-option of interactions from other functions. We tested these hypotheses in the context of a novel phenotype-Lamiales flower monosymmetry - defined by a developmental program that relies on regulatory interaction among CYCLOIDEA, RADIALIS, DIVARICATA, and DRIF gene products. In Antirrhinum majus (snapdragon), representing Lamiales, we tested whether components of this program likely function beyond their previously known role in petal and stamen development. In Solanum lycopersicum (tomato), representing Solanales which diverged from Lamiales before the origin of Lamiales floral monosymmetry, we additionally tested for regulatory interactions in this program.

Results: We found that RADIALIS, DIVARICATA, and DRIF are expressed in snapdragon ovaries and developing fruit, similar to their homologs during tomato fruit development. In addition, we found that a tomato CYCLOIDEA ortholog positively regulates a tomato RADIALIS ortholog.

Conclusion: Our results provide preliminary support to the hypothesis that the developmental program defining floral monosymmetry in Lamiales was co-opted en bloc from a function in carpel development. This expands our understanding of novel trait evolution facilitated by co-option of existing regulatory interactions.
\end{abstract}

Keywords: CYCLOIDEA, Floral monosymmetry, Genetic program, Lamiales, RADIALIS, Solanales

\section{Background}

Convergent traits are novel traits (derived characters, apomorphies) that have recurrently evolved across the tree of life. Interestingly, novel traits usually do not evolve by utilizing new genes, but evolve by co-opting existing genes and genetic programs from other functions. For example, compound leaves, a novelty repeatedly derived in many flowering plant lineages, are defined by recruitment of KNOTTED1-like homeobox (KNOX) genes, a gene family that ancestrally is involved in meristem

*Correspondence: aniketsengupta0@gmail.com

1 Department of Ecology and Evolutionary Biology, University of Kansas,

1200 Sunnyside Avenue, Lawrence, KS 66045, USA

Full list of author information is available at the end of the article development $[1,2]$. However, gene products do not usually function in isolation but interact with other gene products as a part of genetic programs (pathways or networks) to affect phenotype. Hence, it is likely that any gene co-opted towards defining a novel trait was part of a genetic program in the ancestral species. It is not always evident whether individual gene products defining a novel phenotype were co-opted individually from separate networks and assembled into a new network concurrently with the origin of the novelty (de novo assembly), or whether an existing program and set of genetic interactions was co-opted as a unit (en bloc co-option). Few studies have addressed this question [2, reviewed in 3, 4], and mostly in animal systems. In the plant Asparagus, suggestive evidence based on expression of genes in the original author(s) and the source, provide a link to the Creative Commons licence, and indicate if changes were made. The images or other third party material in this article are included in the article's Creative Commons licence, unless indicated otherwise in a credit line to the material. If material is not included in the article's Creative Commons licence and your intended use is not permitted by statutory regulation or exceeds the permitted use, you will need to obtain permission directly from the copyright holder. To view a copy of this licence, visit http://creativecommons.org/licenses/by/4.0/. The Creative Commons Public Domain Dedication waiver (http://creativeco mmons.org/publicdomain/zero/1.0/) applies to the data made available in this article, unless otherwise stated in a credit line to the data. 
cladodes (which are analogous to leaves) indicates that two genetic programs have been co-opted en bloc from leaf to cladode development. First, the program involving KNOTTED1-LIKE HOMEOBOX and ASYMMETRIC LEAVES 1 that defines development of true leaves from meristems [5, reviewed in 6]. Second, the program involving PHABULOSA, REVOLUTA, and miR166, that defines the differentiation of the flattened abaxial-adaxial surfaces of leaves [5, reviewed in 6].

Monosymmetric (bilaterally symmetrical, zygomorphic) flowers are a trait novelty that has evolved at least 130 times from polysymmetric (radially symmetrical, actinomorphic) flowers during the diversification of flowering plants [7]. Monosymmetric flowers have one axis of symmetry that divides the flower into a pair of mirror images; polysymmetric flowers have at least two identical axes. Monosymmetric flowers are often associated with specialized pollination by animals [8, reviewed in 9], and occasionally with wind pollination $[10,11$; possibly because Poaceae flowers are densely packed and monosymmetry potentially increases access to the wind]. Transitions to monosymmetry are strongly associated with increased speciation rates $[12,13]$, consistent with its role as a key morphological innovation, or possibly because the potential for newer pollinators provides ground for species selection [14].

The genetic basis of flower monosymmetry is best understood in the order Lamiales which includes the model species Antirrhinum majus (snapdragon). Monosymmetric flowers evolved early during the diversification of Lamiales $[7,15]$. Therefore, the lineage leading to A. majus has experienced only one shift from polyto monosymmetry, making this an appropriate system to study the genetic basis of this transition. Antirrhinum majus flowers have morphologically distinct dorsal and ventral sides (Fig. 1). Monosymmetry along the dorso-ventral axis in A. majus flowers is defined by a competitive interaction involving TCP (TEOSINTE BRANCHED1, CYCLOIDEA, and PROLIFERATING CELL FACTORS) and MYB (first described from an avian myeloblastosis virus) transcription factors. Both $T C P$ and $M Y B$ genes are found as large gene families in flowering plants $[16,17]$ and play diverse roles beyond flower symmetry patterning, including aspects of vegetative and reproductive development $[16,18,19]$.

The dorsal side of an Antirrhinum flower, excluding the gynoecium, consists of the dorsal sepal, dorsal portions of the lateral sepals, the dorsal petals, the dorsal portions of the lateral petals, and the dorsal sterile stamen (staminodium) whose development is suppressed early in floral development. The identity of dorsal organs in the petal and stamen whorls is defined by the combined action of two recently duplicated TCP paralogs, CYCLOIDEA $(A m C Y C)$ and DICHOTOMA $(A m D I C H)$ [20-23]. These two transcription factors define dorsal flower morphology partly by activating the transcription of a downstream MYB gene, RADIALIS (AmRAD; Fig. 1) [24]. A $m$ RAD protein competes with another MYB protein, DIVARICATA (AmDIV) which defines ventral petal and stamen whorl morphology. Through this antagonistic interaction, AmRAD excludes the ventral flower identity specified by AmDIV from the dorsal side of

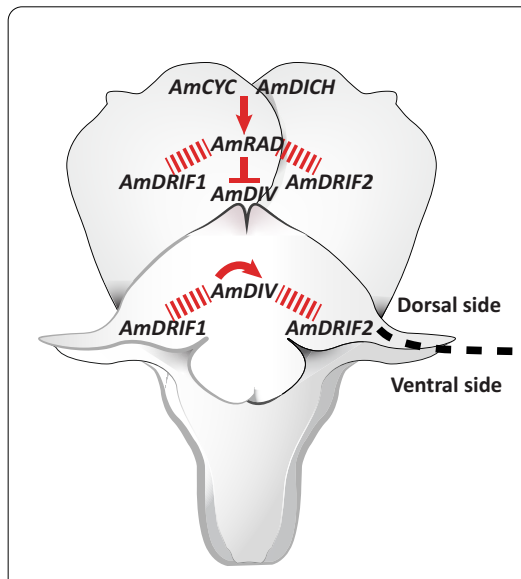

(a)

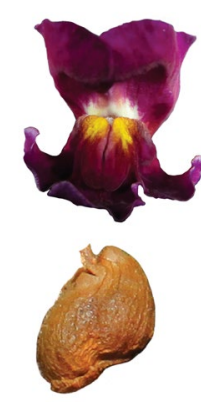

(b)

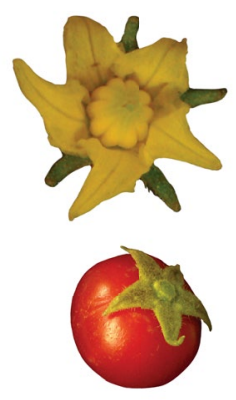

(c)

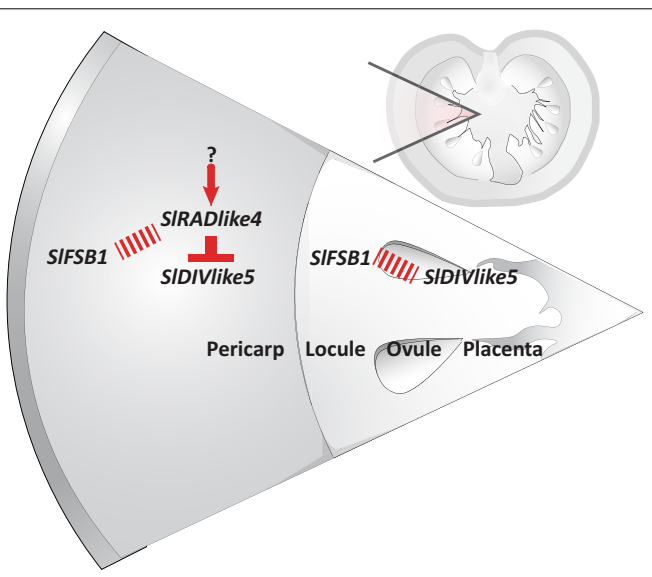

(d)

Fig. 1 Similar genetic interaction controls flower symmetry in A. majus and fruit development in S. Iycopersicum. a Floral monosymmetry in A. majus is defined by a CYC-RAD-DIV-DRIF interaction. b Flower (top) and fruit (bottom) of A. majus. c Flower (top) and fruit (bottom) of S. lycopersicum. d Pericarp development in S. Iycopersicum is defined by a RAD-DIV-DRIF interaction (SIFSB1 is a DRIF homolog). Red arrow: transcriptional activation of a gene by a transcription factor, red inverted-T: negative regulation of one protein by another, red dashed line: protein-protein interaction 
the developing snapdragon flower (Fig. 1). Specifically, $A m \mathrm{RAD}$ and $A m \mathrm{DIV}$ compete for interaction with two other MYB-family protein partners called DIV and RAD Interacting Factors 1 and 2 (AmDRIF1 and AmDRIF2) [24-27] (Fig. 1). AmDIV requires protein-protein interaction with $A m D R I F 1 \& 2$ to function as a transcription factor to regulate downstream targets (Fig. 1) [27, 28]. In the dorsal flower domain, AmRAD outcompetes AmDIV for interaction with $A m D R I F 1 \& 2$, thereby negatively regulating AmDIV function [27].

Evidence strongly supports the hypothesis that $C Y C$, $R A D$, and $D I V$ genes and protein interactions are conserved in specifying monosymmetric flower development dating back to a common ancestor early in the diversification of Lamiales [20, 21, 24, 27, 29-38]. This is not surprising; flower monosymmetry is homologous across Lamiales, derived from a monosymmetric ancestor early in Lamiales diversification (although there have been multiple reversals in derived Lamiales lineages) $[7,15]$. Whether the CYC-RAD-DIV-DRIF interaction was assembled de novo at the base of Lamiales or was recruited en bloc to a role in flower monosymmetry as a pre-assembled unit remains unknown. If the CYC-RAD-DIV-DRIF interaction was recruited as a pre-assembled unit, this would constitute evidence that transitions to floral monosymmetry are facilitated by the presence of an ancestral genetic interaction that can be re-deployed en bloc to a novel role in flower development. To test these hypotheses, it is important to determine whether the CYC-RAD-DIV-DRIF interaction has functions beyond flower monosymmetry in Lamiales, and whether this interaction is also present in an outgroup that diverged from the common ancestor of Lamiales before Lamiales flower monosymmetry evolved.

Solanales are the sister order to Lamiales + Vahliaceae [39] and primarily develop polysymmetric flowers. The Solanales model species, tomato (Solanum lycopersicum), is an ideal outgroup to study the ancestral function of the CYC-RAD-DIV-DRIF network. There are two major groups in Solanales-Convolvulaceae and Solanaceae. Reconstructing ancestral flower symmetry in Solanaceae has been challenging given that the first diverging lineage has monosymmetric corolla. However, recent research suggests that the ancestral Solanales flower likely had polysymmetric corollae [40]. We attempted to develop virus-induced gene silencing in two species from Convolvulaceae (Ipomoea lobata and I. lacunosa), but silencing was only effective in early stages of plant development (data not shown). Hence, Convolvulaceae and early diverging Solanaceae (that have monosymmetric flowers) are not ideal for comparative analysis. Given these issues, we selected S. lycopersicum as a representative of Solanales for comparative analysis.
Compelling data from studies in S. lycopersicum suggest that an RAD-DIV-DRIF interaction plays a role in tomato fruit development by modulating cell size [41]. The RAD component, SlRADlike4 (or fruit SANT/ MYB-like 1, SlFSM1), is an ortholog of $A m R A D ~[42,43]$. SlRADlike4 is primarily expressed in the tomato pericarp [Tomato Expression Atlas, 44] and suppresses cell expansion in that tissue [41] by competing with a DIV-like protein (Fig. 1d). The DIV component, SlDIVlike5 (SlMYBI) is not an ortholog, but a paralog, of $A m D I V ~[42,43]$ (Additional file 1: Fig. S4) and is expressed throughout the developing fruit. Similarly, the DRIF component, Fruit SANT/MYB Binding protein1 (SlFSB1) is also not an ortholog, but a paralog of AmDRIF1\&2 [27] (Additional file 1: Fig. S3). The surprising similarity of this three-component regulatory interaction (Fig. 1) raises the possibility that the common ancestor of Lamiales and Solanales possessed an RAD-DIV-DRIF module to regulate some aspect of plant development and that this module was re-deployed en bloc to a role patterning flower monosymmetry during Lamiales diversification.

The similarity between the RAD-DIV-DRIF module in Solanales and Lamiales can best be explained by two scenarios. One, the RAD-DIV-DRIF evolved independently in Solanales and in Lamiales, and hence the DIV and DRIF components are not orthologous between the RAD-DIV-DRIF interaction reported from Lamiales and Solanales. Alternatively, the RAD-DIV-DRIF interaction evolved before the divergence of Solanales and Lamiales. In the second scenario, the lack of orthology between the A. majus and S. lycopersicum DIV and DRIF components need not exclude the possibility of the RADDIV-DRIF module being homologous. This is because DIV and DRIF proteins are a part of the large protein family of MYB factors making it possible for one DRIF paralog to replace another, or one DIV paralog to replace another, in a genetic interaction, especially if these paralogs have similar biochemical properties. Yeast-twohybrid assays provide evidence that RAD-DIV-DRIF interactions are not ortholog-specific across seed-plants [45]. Indeed, all three clades of DRIFs (Additional file 1: Fig. S3) have at least one member that has been shown to have a DIV-DRIF and RAD-DRIF interaction that is associated with a biological function, suggesting that a DIV-DRIF interaction is likely ancestral to DRIF proteins in Solanales + Lamiales. The three DRIF clades are Group-1 (which includes SIFSB1 that shows DIV-DRIF interaction in tomato fruits), Group-2A (which includes AmDRIF1), and Group-2B (which includes AmDRIF2).

Therefore, despite the lack of strict orthology between the DIV and DRIF components, the RAD-DIV-DRIF interactions displayed by these paralogs may be identical by decent, inherited by Solanales and Lamiales from 
a common ancestor. Two neofunctionalization scenarios can explain the lack of orthology between the $A$. majus and S. lycopersicum DIV and DRIF components: regular neofunctionalization or neofunctionalization associated with paralog replacement. In the first scenario, multiple, ancestral combinations of RAD-DIV-DRIF interactions with overlapping functions existed, but one interaction was neofunctionalized towards monosymmetry [RADDIV-DRIF interactions are not ortholog-specific across seed-plants, at least when tested with yeast-two-hybrids assays, 45]. In the second scenario, a unique, orthologspecific RAD-DIV-DRIF interaction was present in the common ancestor, was neofunctionalized towards monosymmetry, then modified in one of the daughter lineages (where the RAD, or the DIV-DRIF components were replaced by their paralogs). Paralog replacement, in which one paralog replaces another in a biological function, is a documented phenomenon. For example, the replacement of the synaptic function of Acetylcholinesterase1 by its paralog Acetylcholinesterase2 in Cyclorrhapha flies [46].

Here, we tested whether the genes involved in $A$. majus CYC-RAD-DIV-DRIF interaction are expressed, and hence likely functional, in organs not associated with corolla monosymmetry, especially in carpel and fruit development. We also, determined expression patterns for orthologs of these genes in S. lycopersicum. An RAD-DIV-DRIF interaction is already known in S. lycopersicum fruit development [41]. In addition, we tested whether a CYC-RAD interaction is present in S. lycopersicum, by estimating the changes in the transcription of a $S$. lycopersicum $R A D$ ortholog in a S. lycopersicum $C Y C$-downregulated background. We also determined whether presence of predicted TCP/CYC-binding sites in upstream regulatory region of $A m R A D$ orthologs is ancestral to Lamiales + Solanales. Our results suggest that a CYC-RAD-DIV-DRIF interaction may be ancestral to Lamiales and Solanales and may have been co-opted en bloc to flower monosymmetry from another function, likely carpel/fruit development.

\section{Results}

Patterns of AmRAD, AmDIVIDIV-like 1 and AmDRIF1\&2 expression are consistent with a function in carpel and fruit development

We used quantitative real-time PCR (qRT-PCR) to determine relative expression of $A$. majus flower symmetry genes across stages of carpel and fruit development to assess evidence for RAD-DIV-DRIF function during carpel/fruit development similar to that found in tomato [41]. Expression of these genes in organ primordia has already been tested [20, 21, 24, 26]. Therefore, we tested for expression in later stages of carpel and fruit development (carpel and fruit images in Fig. 2). The genes $A m C Y C, A m D I C H, A m R A D, A m D I V, A m D R I F 1$, and $A m D R I F 2$ are involved in defining flower monosymmetry in $A$. majus. The gene AmDIV-like1, a close paralog of $A m D I V$, has not been implicated in the control of flower symmetry, but is important for understanding the ancestral expression and function of its paralog, AmDIV.

We found that upstream regulators of dorsal flower identity, $A m C Y C$ and $A m D I C H$, have relatively high expression in tissues with petals and stamens-inflorescences and entire flower buds (Fig. 3c, d). This is consistent with their singular role in establishing dorsal petal and stamen identity [20,21]. We found $A m C Y C$ and $A m D I C H$ expression to be sparingly low to undetectable in isolated carpel tissue of any stage (Fig. 3c, d).

We found that the dorsal flower identity gene $A m R A D$, is expressed in tissues with petals and stamens-inflorescences and entire flower buds (Fig. 3a), consistent with its previously identified role in establishing dorsal petal and stamen identity [24]. In addition, we found a striking pattern, whereby $A m R A D$ expression peaks in late stages of carpel development, in stage-14 (anthesis) flowers (Fig. 3a). We sequenced the qRT-PCR amplicon from stage-14 carpels and confirmed that the primers were amplifying the correct template. The late high expression of $R A D$ is apparently conserved in the tribe Antirrhineae. The $A m R A D$ orthologs in an early diverging member (Anarrhinum bellidifolium, $A b R A D$ ) and a late diverging member (Linaria vulgaris, $L v R A D$ ) have a peak of expression in carpels at anthesis (Fig. 4). The gene AmRADlike9 has been recently reported from the $A$. majus genome sequence [47]. We report that $A m R A D l i k e 9$ is sister to $A m R A D$; the duplication pre-dates the diversification of Antirrhineae (Additional file 1: Fig. S1). Unlike its paralog, AmRADlike9 has no, or low, expression in carpel tissues (Fig. 3b), but has high expression in vegetative tissue.

Similar to $A m R A D$, the other $M Y B$ genes associated with floral symmetry-AmDRIF1, AmDRIF2, AmDIV, and also $A m D I V$-like 1 -are expressed in carpel tissue but are not localized in the dorsal or the ventral locule (Fig. 3e-h). However, a pattern of localization emerges between two tissues: carpel wall (plus style) vs. ovules (plus septum and placenta). $A m R A D$ is upregulated in the carpel wall relative to the ovules (Fig. 3a), whereas AmDIV-like1 has the opposite localization, being upregulated in in the ovules (Fig. 3f). This provides evidence that a possible competitive interaction between $A m R A D$ and $A m D I V$-like1 may define the development of the two distinct regions of a carpel-the wall and the fertile tissue within. The pattern of localization of AmDIV-like1 that we detect through qPCR (Fig. 3f) is consistent with the in situ mRNA hybridization assays done by previous 

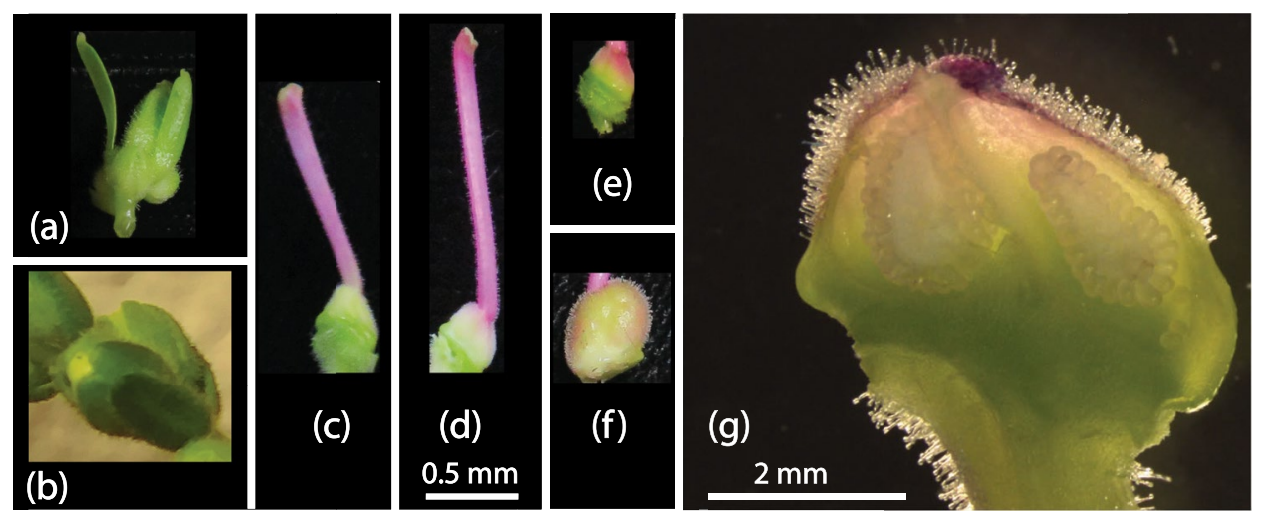

\section{Dorsal side ]『Ventral side}

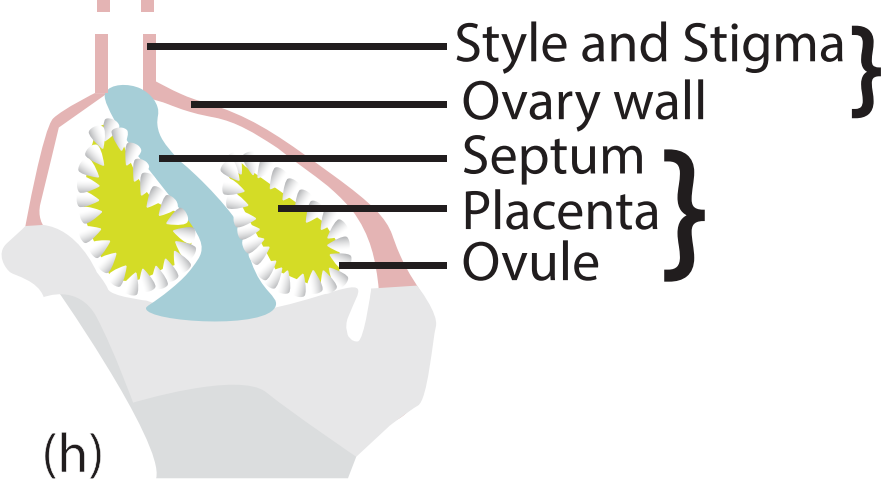

Fig. 2 Antirrhinum majus reproductive tissues for qRT-PCR. a Inflorescence. b Flower bud, stage-11. c Carpel, stage-13. d Carpel, stage-14 (anthesis). e Ovary (developing fruit) 7 days after anthesis. $\mathbf{f}$ Ovary (developing fruit) 11 days after anthesis. $\mathbf{g}$ Longitudinal section of stage-14 ovary. $\mathbf{h}$ Thematic representation of carpel; bracketed tissues were sampled together. Scale bars: $(\mathbf{a}-\mathbf{f}) 0.5 \mathrm{~mm}, \mathbf{f} 2 \mathrm{~mm}$

workers-such as says detect a higher expression of AmDIV-like1 in ovules than in the carpel wall [26]. We did not have access to Amdiv-like1 mutants [26], but we tested for AmDIV-like1 expression in Amrad mutant background (Fig. 5d, next section).

\section{Transcriptional regulatory interactions are limited to positive regulation of $A m R A D$ by $A m C Y C$}

We determined levels of $A$. majus flower symmetry gene expression in available Amcyc, Amdich and Amrad genetic backgrounds (seed sources in Table 1). These data confirm positive regulation of $A m R A D$ by $A m C Y C$ in the inflorescences (Fig. 5a) [24] suggesting that qRTPCR is an appropriate tool to test for such interactions. Beyond the $A m C Y C-A m R A D$ regulatory interaction, we found evidence for only one other transcriptional regulatory interaction: $A m D I V$-like1 expression was significantly reduced in Amrad inflorescences compared to the wildtype (Fig. 5d). The pattern was in the same direction, but not significant, for AmDIV expression in Amrad inflorescences compared to WT (Fig. 5c). Interestingly, the same pattern of reduced AmDIV/AmDIV-like1 expression in the Amrad background was not seen in carpel tissues (Fig. 5c, d). AmCYC does not control the transcription of AmRADlike9, the sister gene of AmRAD (Fig. 5h). AmRADlike9 has one predicted TCP-binding site within the first $3000 \mathrm{bp}$ upstream of its translational start site (Additional file 5: Table S5), suggesting that one such site is insufficient for activation by $A m C Y C$ homologs. We had earlier predicted a cross-regulation between $A m C Y C$ and $A m D I C H$ based on predicted TCPbinding sites [43] but qRT-PCR data provides no such evidence (Fig. 5e, f).

\section{Expression of SITCP7, SITCP26, SIRADlike4, SIDIVlike5, and SIDIVlike6 suggests potential interaction}

We used qRT-PCR to determine relative expression of the homologs of $A$. majus flower symmetry genes in $S$. lycopersicum (Table 2). We found that all the S. lycopersicum genes tested, except for SlRADlike1, are broadly expressed across tomato vegetative and reproductive tissues (Fig. 6). Overlapping expression is an important 


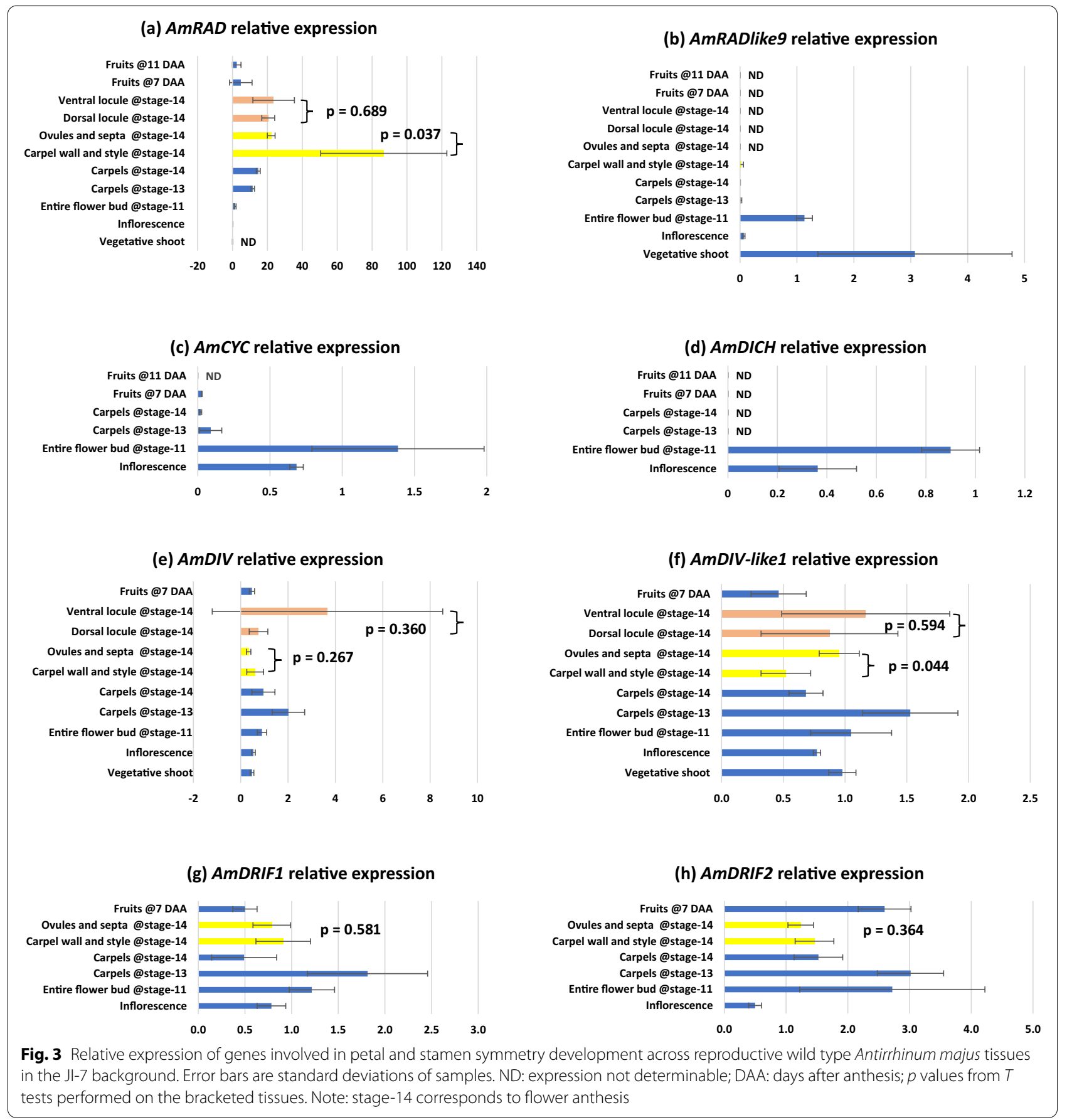

criterion for genes/gene products to interact with each other. Interestingly, the expression of these genes overlaps in carpels and fruits, and is often high in those tissues. This suggests that these genes may have a key role in carpel and fruit development. This is consistent with the previously described interaction of SIRADlike4 and SIDIVlike5 in tomato fruits, where these two proteins compete for SIFSB1 [41], which is a paralog of
$A m$ DRIF1\&2 [27]. In addition, the expression of SlTCP7 and SlTCP26 (orthologs of $A m C Y C / A m D I C H$ ) is not dorsally restricted in flowers (Fig. 6). Instead, SlTCP26 has a pan-floral expression, and both SlTCP7 and SlTCP26 are strongly expressed in the developing fruit as previously demonstrated [19, Tomato Expression Atlas by 44]. 


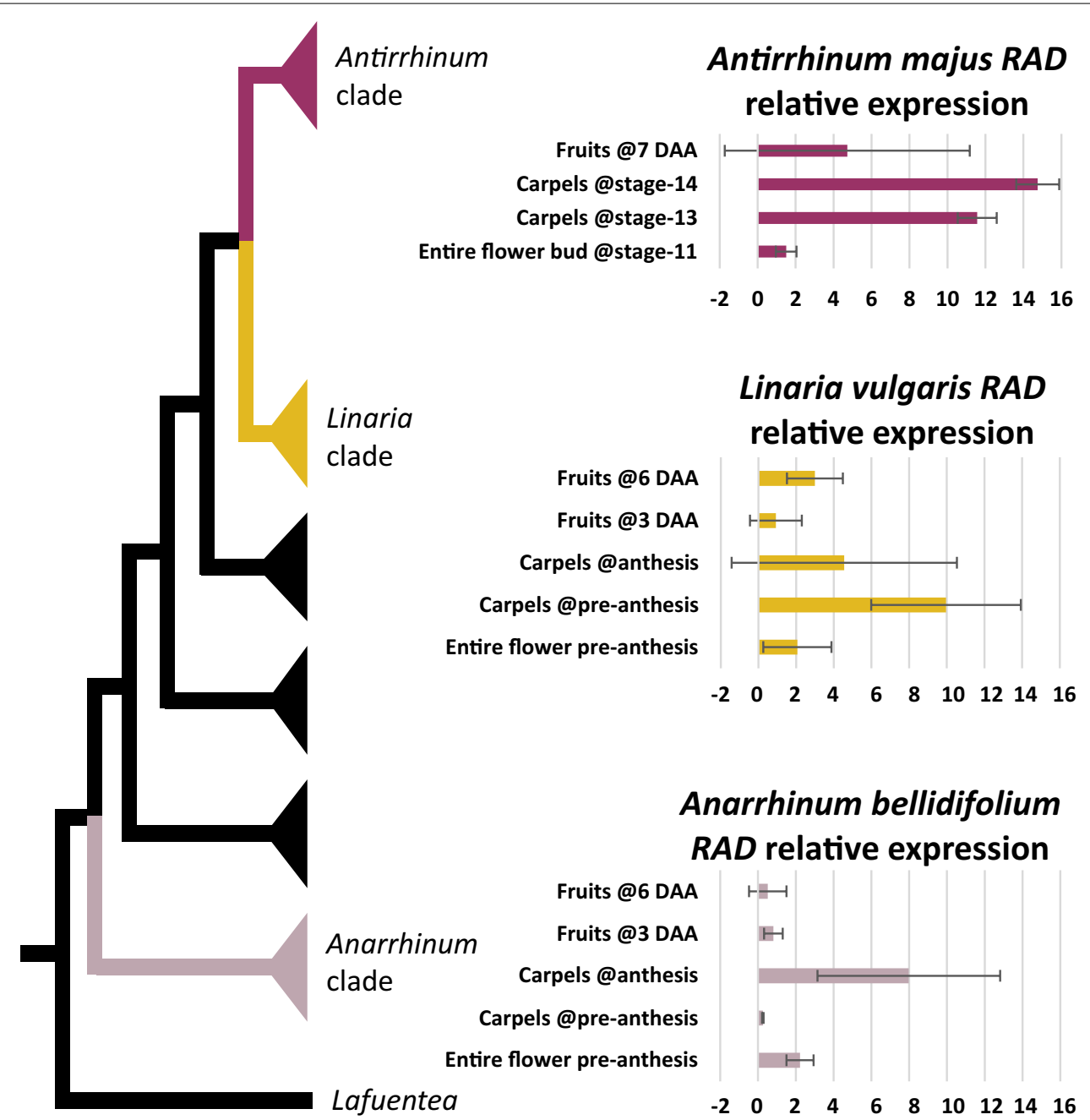

Fig. 4 Relative expression of $R A D$ orthologs in three representative species in the tribe Antirrhineae. The phylogenetic tree represents relationships among these species within the tribe [simplified from 103]

\section{A CYC-RAD regulatory interaction is present in tomato} There are two $A m C Y C / A m D I C H$ orthologs in S. lycopersicum-SlTCP7 and SlTCP26; and there are two AmRAD/AmRADlike9 orthologs in S. lycopersicumSlRADlike1 and SlRADlike4. We selected SITCP26 and SlRADlike4 to test for a $C Y C-R A D$ interaction in flowers. We did not select $S I T C P 7$, because its expression is low in whole stage-20 flowers at anthesis relative to other tissues (Fig. 6a) making downregulation difficult to assess in VIGS experiments (data not shown). We did not select SIRADlike1 for the following two reasons. First, SIRADlike1 is not at all expressed in reproductive tissue, except at a low level in phase-II fruits, making it impossible to test for a CYC-SIRADlike1 regulatory interaction in flowers (SIRADlike1 is expressed at a low level in phase-II fruits; however, these fruits are too small for RNA extraction, and fruits cannot be pooled for RNA extractions given the mosaic nature of VIGS). Second, SIRADlike1 has only one predicted TCP-binding site in the upstream region (Additional file 5: Table S5), hence is unlikely to be under the control of $C Y C$ genes (because the only predicted TCP-binding site upstream of AmRADlike9 could not evoke upregulation by $A m C Y C$, Fig. $5 \mathrm{~h}$ ).

We suspected that SlTCP26 transcriptionally regulates SIRADlike4 based on the following two lines of evidence. First, these two genes are often expressed in the same tissues (Fig. 6b, c). Second, SIRADlike 4 has five predicted TCP-binding sites within the first 3000 bp upstream of its translational start site (Additional file 5: Table S5). We have previously demonstrated that $R A D$ genes that are known or predicted to be under the transcriptional control of CYC proteins are significantly enriched in predicted TCP-binding sites in the first $3000 \mathrm{~kb}$ upstream of their translational start sites [43]. 


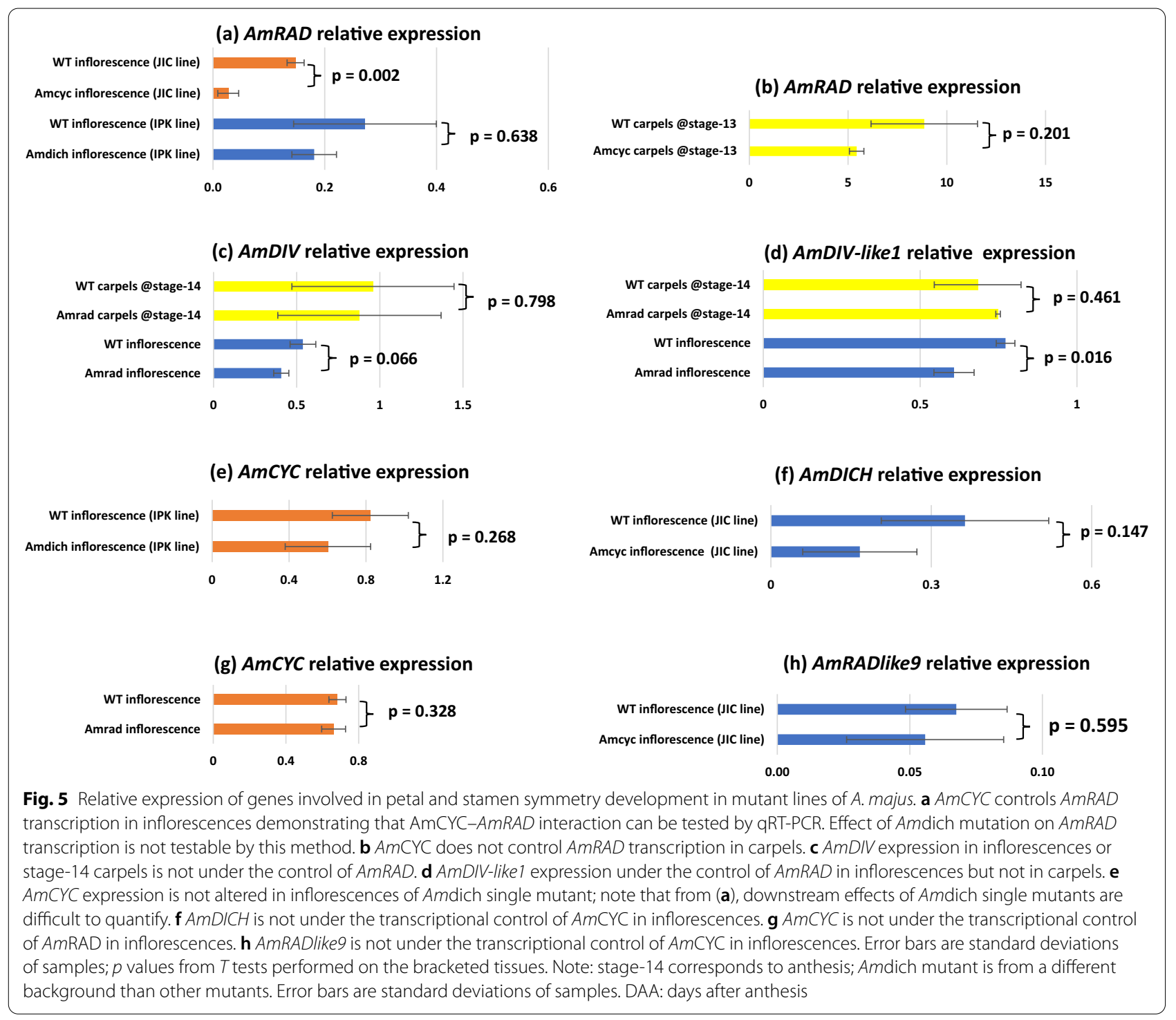

We downregulated SlTCP26 expression in tomato employing VIGS (Fig. 7a) and confirmed downregulation in stage-20 (anthesis) flowers. We found a concomitant decline in SIRADlike4 expression in the same tissues (Fig. 7b). This provides strong evidence that SIRADlike 4 is positively regulated by SlTCP26. We predict this

Table 1 Seed sources

\begin{tabular}{|c|c|c|c|}
\hline Line & Wildtype ID & Mutant ID & Source \\
\hline$A m C Y C$ & $J-7$ & J-608 & The John Innes Centre (JIC), UK \\
\hline $\mathrm{AmDICH}$ & MAM-428 & MAM-95 & $\begin{array}{l}\text { The Leibniz Institute of Plant Genetics and Crop Plant } \\
\text { Research (IPK), Germany }\end{array}$ \\
\hline$A m R A D$ & J-7 & J-654 & The John Innes Centre (JIC), UK \\
\hline AmDIV & $J-7$ & $J-13$ & The John Innes Centre (JIC), UK \\
\hline Solanum lycopersicum & Microtom & Not applicable & Provided by Dr. Vivian Irish, Yale School of Medicine, USA \\
\hline Linaria vulgaris & Accession 15127 & Not applicable & B\&T World Seed \\
\hline Anarrhinum bellidifolium & Accession 1682 & Not applicable & University of Copenhagen Botanical Garden, Denmark \\
\hline
\end{tabular}


Table 2 Orthologs of genes associated with a CYC-RAD-DIV-DRIF interaction

\begin{tabular}{|c|c|c|c|c|c|c|c|}
\hline Species & AmCYC & AmRAD & AmDIV & $\begin{array}{l}\text { SIDIVlike5 } \\
\text { (SIMYBI, } \\
\text { Tomato fruit, } \\
\text { see note) }\end{array}$ & $\begin{array}{l}\text { DRIF Group2a } \\
\text { (AmDRIF1) }\end{array}$ & $\begin{array}{l}\text { DRIF Group2b } \\
\text { (AmDRIF2) }\end{array}$ & $\begin{array}{l}\text { DRIF Group1 } \\
\text { (SIFSB1, tomato } \\
\text { fruit) }\end{array}$ \\
\hline $\begin{array}{l}\text { Antirrhinum } \\
\text { majus }\end{array}$ & $\mathrm{AmCYC}, \mathrm{AmDICH}$ & AmRAD, AmRADlike9 & $\begin{array}{l}\text { AmDIV, AmDIV- } \\
\text { like1 }\end{array}$ & $\begin{array}{l}\text { AmDIVlike10, } \\
\text { AmDIVlike13, } \\
\text { AmDIVlike11 }\end{array}$ & $\begin{array}{l}\text { AmDRIF1, } \\
\text { AmDRIFlike6, } \\
\text { AmDRIFlike7 }\end{array}$ & $\begin{array}{l}\text { AmDRIF2, } \\
\text { AmDRIFlike3 }\end{array}$ & $\begin{array}{l}\text { AmDRIFlike4, } \\
\text { AmDRIFlike5 }\end{array}$ \\
\hline $\begin{array}{l}\text { Solanum lyco- } \\
\text { persicum }\end{array}$ & SITCP7, SITCP26 & $\begin{array}{l}\text { SIRADlike4 } \\
\text { (FSM1), SIRADlike1 }\end{array}$ & SIDIVlike6 & $\begin{array}{l}\text { SIDIVlike5 } \\
\text { (MYBI), SIDIV- } \\
\text { like10 }\end{array}$ & $\begin{array}{l}\text { SIDRIF1, } \\
\text { SIDRIF3 }\end{array}$ & SIDRIF2 & $\begin{array}{l}\text { SIDRIF5 (FSB1), } \\
\text { SIDRIF4 }\end{array}$ \\
\hline Vitis vinifera & GSVIVT01036449001 & GSVIVT01031975001 & DIVlike8 & $\begin{array}{l}\text { DIVlike12, DIV- } \\
\text { like7 }\end{array}$ & DRIFlike2 & $\begin{array}{l}\text { DRIFlike1, DRIF- } \\
\text { like3 }\end{array}$ & DRIFlike4 \\
\hline Oryza sativa & Os03g49880 (OsTB1) & $\begin{array}{l}\text { Os05g50350, } \\
\text { Os12g33950, } \\
\text { Os02g47744 }\end{array}$ & $\begin{array}{l}\text { DIV-like3, DIV- } \\
\text { like4, DIV-like5 }\end{array}$ & $\begin{array}{l}\text { DIV-like1, DIV- } \\
\text { like2 }\end{array}$ & $\begin{array}{l}\text { DRIFlike1, DRIF- } \\
\text { like2 }\end{array}$ & $\begin{array}{l}\text { DRIFlike1, DRIF- } \\
\text { like2 }\end{array}$ & $\begin{array}{l}\text { DRIFlike3, DRIF- } \\
\text { like4, DRIFlike5, } \\
\text { DRIFlike6 }\end{array}$ \\
\hline References & {$[16,102]$} & $\begin{array}{l}\text { Additional file 1: Fig. } \\
\text { S1, }[45,63]\end{array}$ & $\begin{array}{l}\text { Additional } \\
\text { file 1: Figs. S1 } \\
\text { and S4, }[45,63]\end{array}$ & $\begin{array}{l}\text { Additional } \\
\text { file 1: Figs. S1 } \\
\text { and S4 }\end{array}$ & $\begin{array}{l}\text { Additional } \\
\text { file 1: Fig. S3 }\end{array}$ & $\begin{array}{l}\text { Additional } \\
\text { file 1: Fig. S3 }\end{array}$ & $\begin{array}{l}\text { Additional file 1: } \\
\text { Fig. S3 }\end{array}$ \\
\hline
\end{tabular}

Relationships among close homologs of SIDIVlike5 are not well-resolved beyond Solanales + Lamiales. The V. vinifera and O. sativa genes could be orthologs or close paralogs of SIDIVlike5

transcriptional control to be direct-SlTCP26 likely binds to the predicted TCP-binding sites present upstream the translational start site of SIRADlike4 (Additional file 5: Table S5). This provides preliminary evidence of a CYC$R A D$ regulatory interaction in tomato.

\section{A CYC $-R A D$ regulatory interaction is likely ancestral to Lamiales + Solanales}

We predicted TCP-binding sites within the first $3000 \mathrm{bp}$ upstream of the translational start sites of AmRAD orthologs in Solanales and Lamiales (Additional file 5: Table S5), then estimated the ancestral state of this character across Lamiales + Solanales. Presence of at least two predicted TCP-binding sites in the 3000 bp upstream region is homologous between AmRAD and SlRADlike4, and is ancestral to Lamiales + Solanales (Fig. 8). This provides predictive, bioinformatic evidence that the CYC$R A D$ interaction seen in A. majus and S. lycopersicum are homologous.

\section{Discussion}

Expression of AmRAD, AmDIVIDIV-like 1, and AmDRIF1\&2 are consistent with a function in carpel development independent of dorso-ventral identity

We identified a novel peak in $A m R A D$ expression late in carpel/fruit development. This indicates a potentially important developmental function in later stages of carpel/fruit development, especially in the carpel wall, where $A m R A D$ expression is highest. This function is likely independent of fruit symmetry, because the key genes associated with corolla symmetry-AmCYC, AmDICH, AmRAD, AmDIV, as well as AmDIVlike1-are either expressed at statistically equivalent levels in both the dorsal and the ventral locules, or are not significantly expressed in carpels at all (Fig. 3). AmCYC is expressed at extremely low levels in carpels (Fig. 3c) but this is likely background expression and not functional because of the following two reasons. First, because $A m R A D$ expression remains unaltered stage-13 carpels of $A m c y c$ mutants (Fig. 5b). Second, because later in fruit development, (fruits 11 days after anthesis), $A m R A D$ continues to express even though $A m C Y C$ (and $A m D I C H$ ) are not expressed (Fig. 3a, c, d). CYC orthologs in early diverging Lamiales are expressed in the carpels [36]. It is possible the expression in carpels has been lost/reduced in the line leading to $A m D I C H$ and $A m C Y C$.

$A m C Y C-A m R A D$ interaction has a non-cell-autonomous function in defining the monosymmetric carpels/ fruits in A. majus, where the two locules of the carpels/ fruits have distinct morphology (images of mutant in Additional file 1: Fig. S2) [unpublished data available in thesis 48]. This function does not involve dorsoventrally distinct transcription of $A m C Y C$ or $A m R A D$ in the carpels, but likely involves the movement of AmRAD proteins from the dorsal petals to the dorsal locule of the carpel [similar to migration to lateral petals hypothesized in 24]. This mutant morphology is consistent with that seen in the fruits of the cyc mutant of another Lamiales species Misopates orontium [49]. However, carpel monosymmetry is patterned in early stages of carpel development, and not at or near flower anthesis (where the peak of $A m R A D$ transcription is seen, Fig. 3a), and this function in carpel symmetry is dependent on $A m C Y C$. Hence, we predict that $A m R A D$ 


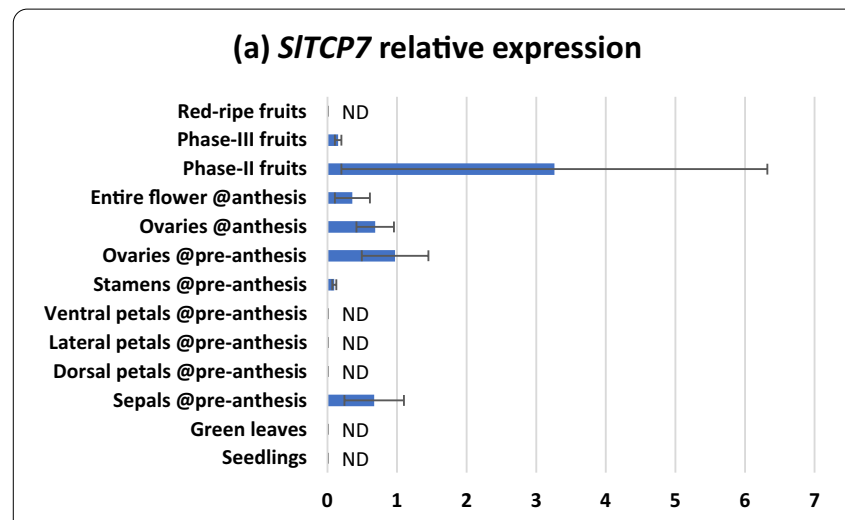

(c) SIRADlike4 relative expression

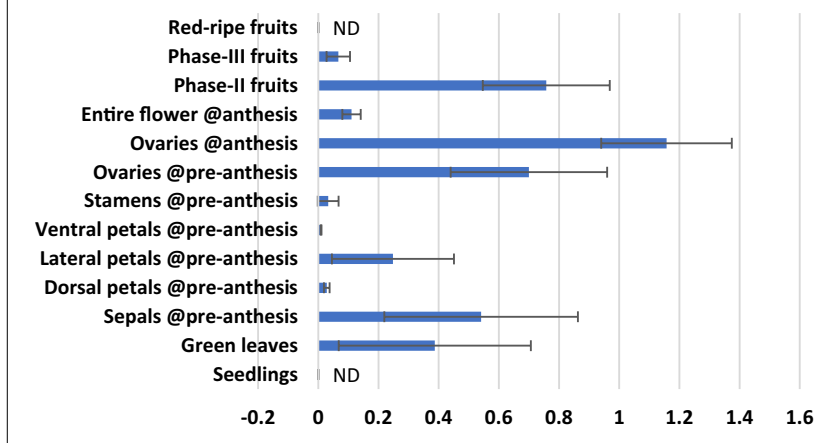

(e) SIDIVlike6 relative expression

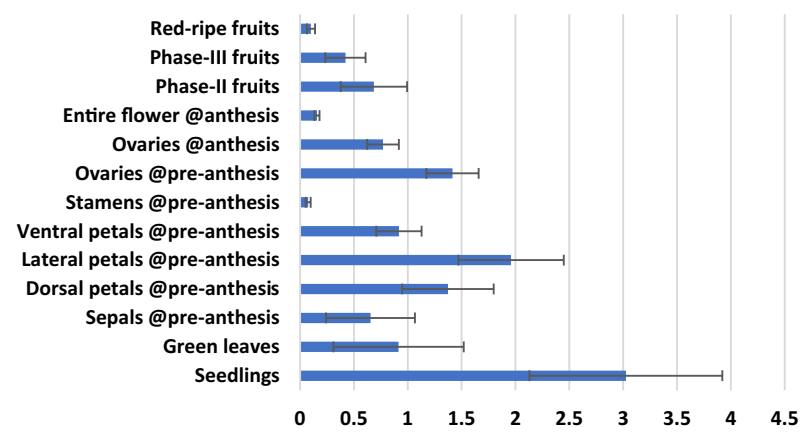

(b) SITCP26 relative expression

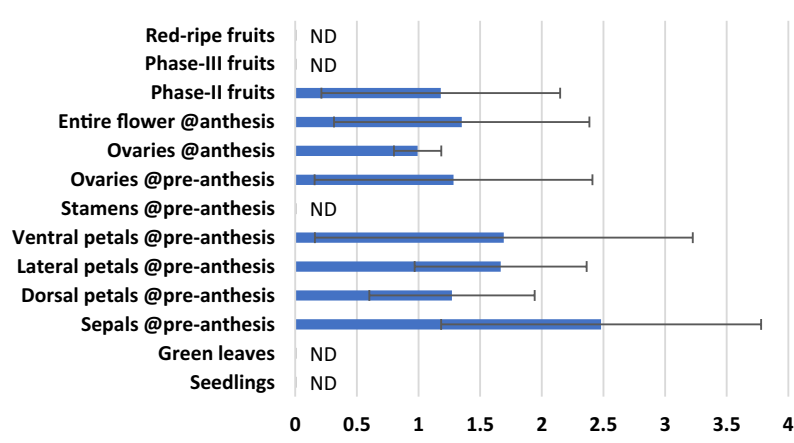

(d) SIRADlike1 relative expression

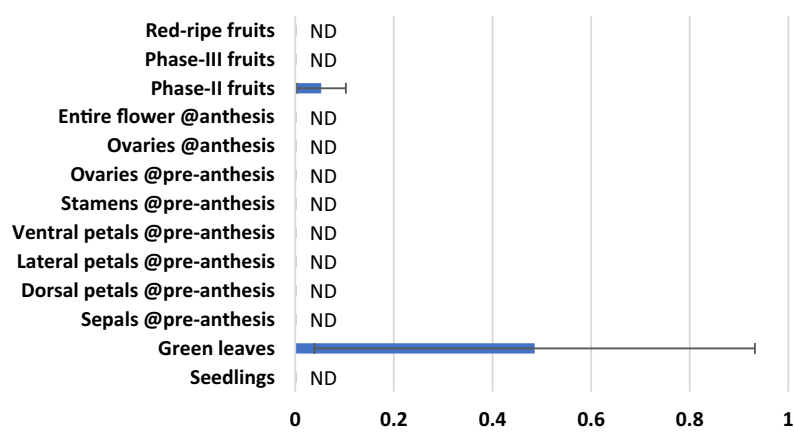

(f) SIDIVlike5 (SIMYBI) relative expression

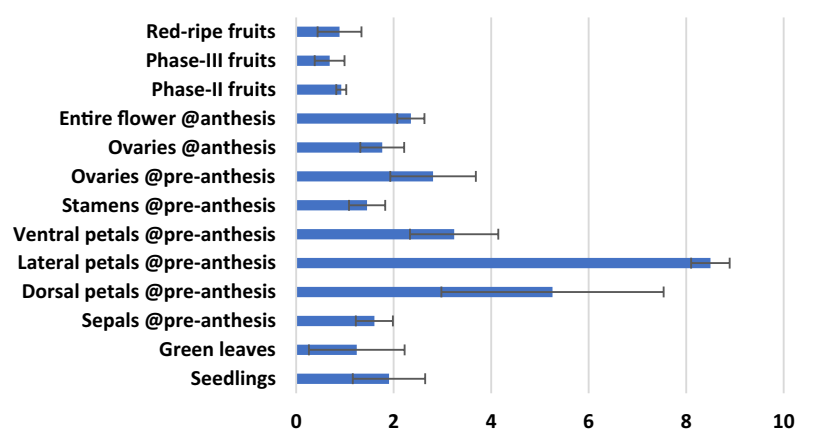

Fig. 6 Relative expression of CYC, RAD and DIV orthologs and one DIV paralog in wildtype Solanum lycopersicum across reproductive organs. Error bars are standard deviations of samples. ND: expression not determinable. Note: anthesis is stage-20; pre-anthesis is stage-16

\section{SITCP26 relative expression}

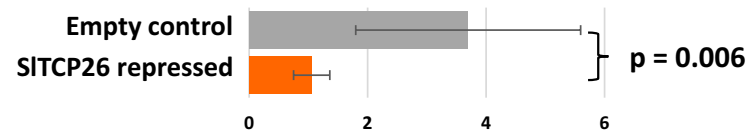

(a)
SIRADlike4 (SIFSM1) relative expression

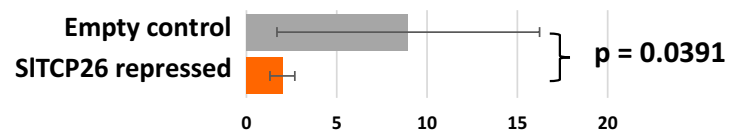

(b)

Fig. 7 Downregulation of SITCP26 (a) and its effect on SIRADlike4 (b). Error bars are standard deviations of samples. The $p$ values are from $T$ tests performed on the bracketed tissues assuming equal variances (determined by Levene's Test). Samples sizes are eight and six, respectively, for control and repressed lines 

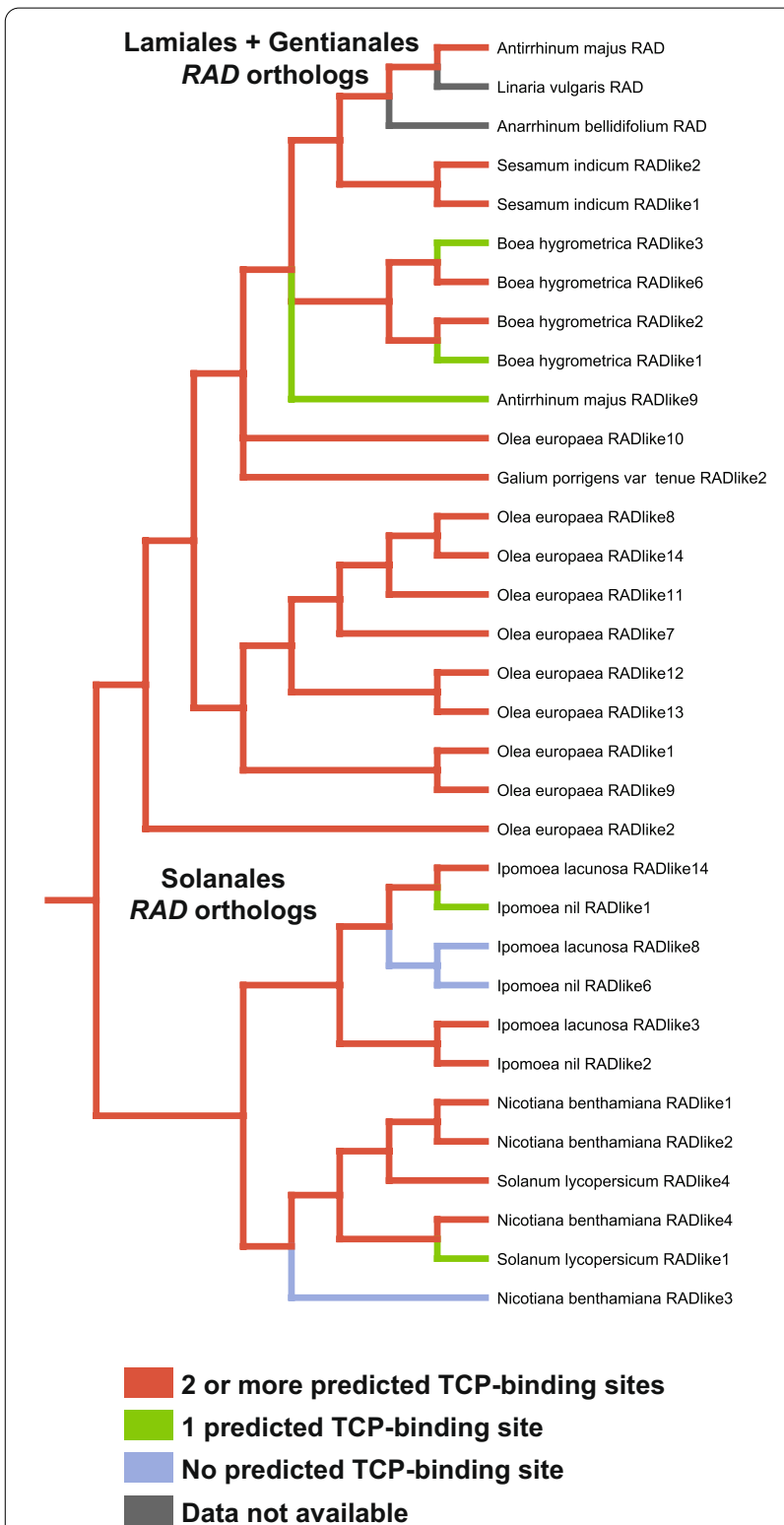

Fig. 8 Parsimony based ancestral state reconstruction of the number of predicted TCP-binding sites present within the first $3000 \mathrm{bp}$ upstream of the translational start sites of AmRAD orthologs in Lamiales and Solanales. The ancestral RAD gene had at least two predicted TCP-binding sites upstream of its translational start site phenotype of the second function would require extensive anatomical analyses best suited for a follow-up study.

The peak of $A m R A D$ transcription in carpels at anthesis (Fig. 3a) likely controls the second, hitherto untested phenotype in the later stages of carpel/fruit development. It is likely that this function involves $A m \mathrm{RAD}$ competitively excluding AmDIV/DIV-like1 from interacting with $A m D R I F 1 / 2$. This hypothesis is based on the following lines of evidence. First, high expression of $A m R A D$ in carpels coincides with expression of AmDIV/DIV-like1 and AmDRIF1E2 in those tissues, and second, the only biochemical interactions known for AmRAD homologues involve competition with $A m$ DIV/DIV-like1 homologs for $A m \mathrm{DRIF} 1 / 2$ interaction. $A m \mathrm{CYC} / A m \mathrm{DICH}$ downregulate $A m D I V$ in stage10 flowers [26] possibly by upregulating $A m \mathrm{RAD}$ which in turn may disrupt $A m D I V$ autoregulation. However, we find that the Amrad mutant background does not alter $A m D I V$ expression in stage-14 carpels or in inflorescences (Fig. $5 \mathrm{c}$ ).

Hence, the AmCYC/AmDICH control over AmDIV is either limited to stage-10 flowers or is mediated by factors other than AmRAD. We had predicted an $A m \mathrm{CYC}-\mathrm{AmDICH}$ cross-regulation [43], but do not find any evidence for $A m C Y C$ transcriptionally regulating $A m D I C H$ (Fig. 5f). The effects of Amdich mutation on downstream genes is difficult to quantify in single mutants (Fig. 5a) [24], but we predict them to be similar to $A m c y c$. Therefore, it is unlikely, that $A m C Y C-A m D I C H$ regulate each other, or even themselves. The predicted TCP-binding sites upstream of $A m C Y C$ and $A m D I C H$ are potentially bound by other TCP proteins, as in Gerbera hybrida [50]. Alternatively, $A m \mathrm{CYC} / \mathrm{AmDICH}$ have a complex interaction-this is based on the evidence that in Torenia fournieri, another Lamiales species, the expression of a $C Y C$ ortholog TfCYC1 declines irrespective of whether another ortholog $T f C Y C 2$ is upregulated or downregulated [33]. We also report that $A m R A D$ does not affect the transcription of $A m C Y C$, unlike its ortholog TfRAD1 in Torenia fournieri [33].

\section{A conserved ancestral function of RAD-DIV-DRIF in fruits may pre-date Lamiales flower monosymmetry}

In Lamiales, $A m$ RAD is known to function in defining floral monosymmetry along the dorso-ventral axis, and monosymmetry evolved in Lamiales after its from its close relative Solanales. Solanum lycopersicum is a model species in the order Solanales, and in whose fruits an RAD-DIV-DRIF like interaction has been reported [41]. In this interaction, the RAD component 
suppresses cell expansion in the pericarp tissue. Pericarp, or the fruit wall, is the ovary wall after fertilization. We provide suggestive evidence that $A m \mathrm{RAD}$ has a function in late carpel/fruit development, and that this function may involve $A m D I V, A m D I V$-like1, and $A m D R I F 1 \& 2$ in that expression of these gene overlaps with expression of $A m R A D$ in later stages of carpel development. Hence, we hypothesize an ancestral function of $R A D$-like genes is in controlling micromorphology during carpel wall development. An $R A D$ function in carpels is likely ancestral to Lamiales-RAD is expressed in the carpels of early diverging Lamiales [36], as well as in later diverging Lamiales-Plantaginaceae (this study), Phrymaceae [51], and Lamiaceae [51]. Similarly $C Y C$ is expressed in the carpels of early diverging Lamiales [36], Phrymaceae, [51], and Lamiaceae [51], with an exception in A. majus (where expression is low or undetectable). This suggests that a $C Y C$ and $R A D$ co-expression, and possibly, interaction, in carpels is ancestral to Lamiales, with a later loss of CYC expression in Antirrhineae carpels. This also suggests that the RAD-DIV-DRIF interaction, which is crucial in defining Lamiales monosymmetry, did not evolve during the origin of flower monosymmetry in Lamiales but was co-opted from a different function, likely fruit/carpel development, to define the dorsoventral monosymmetry in Lamiales flowers.

\section{SITCP26 transcriptionally regulates SIRADlike4 in tomato} Downregulating SITCP26 by VIGS leads to a corresponding decrease in SIRADlike4 expression. This provides strong evidence for transcriptional control of SIRADlike4 by SlTCP26. However, our data do not provide evidence as to whether this interaction is direct (SlTCP26 protein binding to the $5^{\prime}$ cis-regulatory sequence of SlRADlike4) or indirect (downstream targets of SlTCP26 binding to the $5^{\prime}$ cis-regulatory sequence of SlRADlike4). TCP proteins (similar to SlTCP26) are known or predicted to be transcription factors that bind to the consensus TCPbinding site $5^{\prime}-\mathrm{GGNCCC}-3^{\prime}[35,52,53]$. RAD orthologs that are known or predicted to be under the direct transcriptional regulation by $C Y C$ orthologs are likely to be enriched in predicted TCP-binding sites in the first $3000 \mathrm{~kb}$ upstream their translational start site [43]. SlRADlike4 has five such predicted TCP-binding sites within the first $3000 \mathrm{~kb}$ upstream of its translational start site. Together, the data from bioinformatics analysis and gene silencing experiments suggest that SlTCP26 directly upregulates the transcription of SIRADlike4. Whether the transcriptional control of SlRADlike4 by SITCP26 is direct can be verified by DNA-protein interaction studies. One such test could be a yeast-hybrid assay that determines whether the protein SlTCP26 can activate transcription by acting on wild-type promoter of SlRADlike4 but cannot activate transcription when the GGNCCC sites in the promoter are modified or deleted. Such studies are beyond the scope of this work. There were no noticeable differences between the populations treated with empty pTRV2 vs. pTRV2-SlTCP26 in terms of flower size and symmetry, and petal number (data not shown). However, it is possible that SlTCP26 controls micromorphological features, like cell number or size, in flowers. Tomato plants often bear flowers with additional floral organs in any whorl (called 'megablooms' in horticulture). Such megabloom flowers appeared in untreated wildtype, empty pTRV2 treated, and pTRV2SITCP26 treated populations. Therefore, it is unlikely that VIGS-associated downregulation of SlTCP26 is responsible for this phenotype. The population treated with pTRV2-SITCP26 developed flower buds $c a$. 10 days before the empty pTRV2 treated population. Further experiments are needed to quantify this shift. It is not surprising that silencing of a $C Y C$ ortholog did not have obvious morphological effects in S. lycopersicum, even though molecular testing confirms a downregulation. Tracking the function of the CYC ortholog AtTCP1 in Arabidopsis thaliana has also been difficult. Traditional silencing methods (including RNA interference) could not reveal the function of AtTCP1 [54, 55]. The function of $A t T C P 1$ was revealed when a chimeric $A t T C P 1$ fused to a transcriptional repressor domain was over-expressed [55]. However, this method is not appropriate for studying the function of SIRADlike4 or its upstream regulator SITCP26, because strong downregulation of SIRADlike4 kills all transformants [41].

\section{CYC-RAD-DIV-DRIF interaction was likely co-opted to flower monosymmetry from other functions}

A CYC-RAD-DIV-DRIF interaction defines flower monosymmetry in Lamiales. A part of this interaction, RAD-DIV-DRIF interaction, is present in Solanales, and affects fruit development in tomato [41]. We provide preliminary evidence that the RAD-DIV-DRIF interaction is conserved across Lamiales + Solanales carpel/fruit development. Here we report a CYC-RAD interaction in tomato, where $S l \mathrm{TCP} 26$ transcriptionally upregulates SlRADlike4 (Fig. 7b). This would suggest that the entire CYC-RAD-DIV-DRIF interaction is likely ancestral to Lamiales + Solanales, and was co-opted en bloc to define the novel phenotype of flower monosymmetry in Lamiales. However, this conclusion is diminished by the fact that AmRAD and SlRADlike4 have sister genes that we demonstrate or predict to not be under the control of AmCYC and SlTCP26. These two contrasting lines of evidence can be explained by two hypotheses. First, the 
CYC-RAD interaction in A. majus and S. lycopersicum are not homologous, and evolved independently. Second, the CYC-RAD interaction in $A$. majus and $S$. lycopersicum are homologous, but the CYC-RAD interaction has been lost in some paralogs. If the second hypothesis is true, then the presence of two or more predicted TCP-binding sites upstream of $A m R A D$ and SIRADlike4 should be homologous, the state being ancestral to Lamiales + Solanales.

We conservatively expect that the presence of a single TCP-binding site within the 3000 bp immediately upstream of the translational start site is insufficient to invoke regulation by AmCYC and its orthologs but having two can be sufficient. This prediction is based on the following two lines of evidence. First, we demonstrate that AmRADlike9, which has one predicted TCP-binding site within the first $3000 \mathrm{bp}$ upstream of its translational start site (Additional file 5: Table S5), is not under the transcriptional control of $A m C Y C$ (Fig. 5h). Second, having two or more such sites is likely functional, because $A m R A D$ [under the control of AmCYC, 52] and AtDWARF4 [under the control of AmCYC ortholog in Arabidopsis, AtTCP1, 56] each have two such sites in their upstream region.

Our ancestral state reconstruction supports the second hypothesis that the presence of two or more predicted TCP-binding sites upstream of $A m R A D$ and SIRADlike4 is homologous, the state being ancestral to Lamiales + Solanales (Fig. 8). This provides evidence that a CYC-RAD interaction is ancestral to Solanales + Lamiales, with the likely ancestral function of this interaction in carpel/fruit development. The lack of significant $A m C Y C$ expression in $A$. majus carpels/fruit likely represents a loss, because in early diverging Lamiales, both $C Y C$ and $R A D$ genes are expressed during carpel development $[36,51]$.

\section{Explaining the repeated recruitment of CYC-RAD-DIV- DRIF interaction}

Since the initial discovery of CYC function in $A$. majus flower symmetry, $C Y C$ orthologs have been implicated in defining independently derived floral monosymmetry in many major clades of flowering plants [reviewed in 57]. A role for CYC-RAD-DIV interaction (DRIF participation not tested) has been suggested in the development of monosymmetric flowers in the order Dipsacales [58-61], and potentially in magnoliids $[62,63]$. A similar, TCP-RAD-DIV-DRIF interaction is possibly involved in orchid monosymmetry $[64,65]$. The repeated parallel recruitment of $C Y C$ orthologs in defining floral monosymmetry has been explained with the following model. An ancestral dorsal-specific expression of CYC was already present in the polysymmetric ancestral flowers
[66]; this ancestral dorsal-specific expression would generate a bias, where $C Y C$ would be more likely to be coopted in defining any new morphology evolving in the dorsal floral organs. This model is based on the observation that in Arabidopsis thaliana, which has non-monosymmetric flowers at maturity, the CYC ortholog AtTCP1 is expressed in the dorsal region of the floral primordium [66]. The applicability of this model across eudicots has been questioned [43], because several lines of evidence demonstrate that a dorsal-specific expression is likely not ancestral to eudicots, or even Brassicaeae. Within Brassicaceae, monosymmetric flowers do not have an Arabidopsis-like dorsally restricted $C Y C$ expression in their primordia (but the expression is dorsally restricted later during petal development) [67]. AtTCP1 expression is not limited to the dorsal side of the floral meristem, but is widely expressed in other parts of the plant [55], and this is distinct from the expression pattern of $A m C Y C$ $/ A m D I C H$. Even within Lamiales, dorsally restricted $C Y C$ and $R A D$ expression is clearly a derived state-early diverging Lamiales (that have non-monosymmetric flowers) have pan-floral expression [36]. This expression pattern of early diverging Lamiales is consistent with the expression pattern we report in in S. lycopersicum. That is, the expression of $C Y C$ orthologs in S. lycopersicum is not restricted to the dorsal petals in the polysymmetric flowers of tomato, at least in later stages of flower development (this is in contrast with $A$. majus, where $A m C Y C$ expression remains restricted to dorsal organs even in late stages of development, namely, stage 9) [in situ in 20, PCR in 21, stage identified from 68]. This provides evidence that the dorsal-specific expression of $A m C Y C$ / $A m D I C H$ and their orthologs in later-diverging Lamiales is an innovation of Lamiales, and that the polysymmetric flowers of the ancestors of Lamiales + Solanales likely did not have such dorsally restricted $C Y C$ expression.

These lines of evidence demonstrate that the ancestral expression of $C Y C$ in Brassicales (which includes $A$. thaliana) or Lamiales + Solanales (which includes $A$. majus) was not dorsally restricted. But then, what expression pattern of $C Y C$ (and $R A D, D I V$, and $D R I F$ ) genes is likely ancestral across eudicots, and possibly angiosperms? There are two alternative scenarios. First, the expression pattern seen in S. lycopersicum (CYC expression pan-floral, pan-plant) is ancestral, and second, the one represented by $A$. thaliana and $A$. majus (CYC restricted to dorsal side of flower/floral primordium) is ancestral. There has been no evidence outside $A$. thaliana, where a flower with ancestrally polysymmetric flowers displayed a dorsally restricted $C Y C$ expression, but several lines of evidence support the first scenario. For example, in an early diverging eudicot, Eschscholzia californica (which has non-monosymmetric flowers), the expression 
of one of the two AmCYC orthologs is at organ boundaries, and the other is across the floral meristem [69], and neither is dorsally restricted. In addition, we looked in the published expression data of two other angiosperms outside the Lamiales + Solanales clade and the Brassicales clade: the rosid Vitis vinifera (Additional file 10) and the monocot Oryza sativa (Additional file 11). In these two outgroup species, we investigated the expression of the orthologs of the genes involved in $A$. majus flower symmetry $(A m C Y C, A m R A D, A m D I V$, and $A m D R I F 1 / 2)$ and of their homologs involved in S. lycopersicum fruit development (SIRADlike4, SIMYBI, and SIFSB1). These orthologs in the outgroups show a plantwide expression and are often upregulated in carpel/fruit tissue. For example, the $A m R A D$ ortholog Vitis vinifera (GSVIVT01031975001) is strongly upregulated in carpel tissues (Additional file 10: Fig. S2), similar to the AmDIV ortholog Vitis vinifera DIVlike8 that is strongly upregulated in carpels and fruits (Additional file 10: Fig. S3). Clearly, the expression of the $C Y C$ orthologs in Brassicales (except $A$. thaliana), in early Lamiales, in Solanales, in $V$. vinifera and in O. sativa, is not restricted to flowers (unlike in A. majus), and/or when expressed in flowers/ floral meristems, the expression is not dorsally restricted (unlike in A. majus or A. thaliana). These lines of evidence support our hypothesis that the ancestral expression of $C Y C$ and $R A D$ was not restricted to the dorsal side of flowers, and the expression pattern in $A$. majus is derived.

Hence, the model explaining the repeated recruitment of $C Y C$ towards defining floral monosymmetry by hypothesizing an ancestrally dorsally restricted $C Y C$ expression is unlikely to be applicable. Then, the question persists-why would a CYC-RAD-DIV-DRIF interaction, and not any other genetic interaction, be recruited for flower monosymmetry in Lamiales (and in other flowering plant lineages)? We provide evidence that CYC-RAD-DIV-DRIF interaction likely pre-dates the origin of flower monosymmetry in Lamiales, and its ancestral function was likely in carpel/fruit development. There is suggestive evidence that an RAD-DIVDRIF interaction, and possibly, CYC-RAD-DIV-DRIF is ancestral to all flowering plants (or at least to magnoliids, monocots, and eudicots) and was possibly involved in carpel development, because it has been reported or hypothesized across many angiosperm lineages. For example, an RAD-DIV-DRIF interaction has been biochemically tested (but not functionally validated) in Arabidopsis thaliana, where at least one $R A D$ ortholog is expressed in carpels (AtRL2, At2g21650) and all of the DIV orthologs can bind to a DRIF paralog (AtFSB1, At1g10820; not all DRIF homologs tested) [DRIF homology from 27, protein interaction from 41, DIV homology from 59, 70]. Expression of $C Y C, R A D$, and $D I V$ genes in carpels and fruits is a recurrent pattern in angiosperms, including in magnoliids [ $C Y C$ in 62, RAD and $D I V$ in 63], orchids $[R A D$ and $D I V$ in 71], possibly in early core eudicots [CYC in 69, carpels and stamens pooled as one tissue], in lamiids [CYC and $R A D$ in 36,51$]$, rosids [RAD in 70], and campanulids [CYC in 50]. The evidence for this function to be in carpel development is the strongest, but is not limited to those organs. Indeed, in tomato, $C Y C$, $R A D$, and $D I V$ are expressed, to a varying degree, in all floral organs in addition to vegetative organs.

We propose that CYC-RAD-DIV-DRIF interaction was co-opted towards defining floral monosymmetry for the following three reasons. First, because the interaction was already available; second, because the core interaction is based on protein-protein competition from which the competing components (RAD and DIV) could be recruited to define opposite sides of the flower; and third, because co-option of CYC-RAD-DIV-DRIF interaction to flower monosymmetry would require only one evolutionary step of making $C Y C$ expression dorsal-specific. $C Y C, R A D$, and $D I V$ likely had a pan-floral expression in the common ancestors of Lamiales + Solanales as estimated from the expression pattern in representative species [DIV from this work and 27, DRIF from 27, CYC and $R A D$ from this work and 36]. The ancestral expression pattern of DRIF is not clear, but given its polysymmetric expression in A. majus flowers, it is likely that it too was ancestrally pan-floral in expression irrespective of symmetry. This non-localized, pan-floral activity of this interaction could be partitioned to define floral monosymmetry-one side defined by a strong RAD activity, the other by a strong DIV activity, with lateral organs being defined at the boundaries of these two zones in a density-dependent manner. The strong, dorsally restricted activity of RAD can be acquired by a change in the expression pattern of its transcriptional upregulator $C Y C$. The expression pattern of the other two genes, $D I V$ and DRIF, need not have undergone any major changes. Thus, the evolution of CYC-RAD-DIV-DRIF interaction seen in monosymmetric flowers of $A$. majus from a pan-floral CYC-RAD-DIV-DRIF interaction of the polysymmetric ancestral flower would require a single evolutionary change-the expression of $C Y C$ having evolved a dorsally restricted pattern. In A. majus, this change is likely represented by the putative cis-regulatory sequence located $4.2 \mathrm{~kb}$ upstream of $A m C Y C$ translational start site. When this site is disrupted by transposon insertion in the backpetal mutants, the expression of $A m C Y C$ becomes pan-floral [21].

Existing genes are often recruited to define novel phenotypes [72, 73]. Co-option of single genes in defining novel phenotypes has been reported from a wide variety 
of organisms, including the co-option of CYC to define flower monosymmetry [73-78]. We provide preliminary evidence that the CYC-RAD-DIV-DRIF interaction that defines flower monosymmetry in Lamiales was coopted en bloc from another function, likely female organ development, and was not assembled de novo near the base of Lamiales. This is consistent with the en bloc cooption reported in other organisms. [72, 75, 79, 80]. Our results add to the evidence that evolution of novel phenotypes can be associated with or facilitated by the cooption of entire genetic interactions.

\section{Conclusions}

The CYC-RAD-DIV-DRIF interaction is critical for flower symmetry in Lamiales, but its origin had remained unresolved. We provide preliminary support to the hypothesis that this program was co-opted en bloc from a function in carpel/fruit development. We also raise the hypothesis that the program is ancestral to a wider group of flowering plants and was hence recruited repeatedly towards defining independently derived-monosymmetric flowers. This is in line with the idea that the evolution of novel traits is facilitated by co-option of existing regulatory interactions.

\section{Materials and methods}

\section{Plant material}

The following species were studied in this work: Antirrhinum majus L., Sp. Pl. 2: 617 (1753), Solanum lycopersicum L., Sp. Pl. 1: 185 (1753), Linaria vulgaris Mill., Gard. Dict., ed. 8. [unpaged] Linaria no. 1 (1768), and Anarrhinum bellidifolium Fenzl ex Jaub. \& Spach, Illustr. Pl. Or. v. 54 (names from www.ipni.org). Seed sources are listed in Table 1. We imported A. majus seeds under USDAAPHIS permit P37-16-01034. We germinated and maintained the plants under $16 \mathrm{~h}$ daytime at $20-26^{\circ} \mathrm{C}$.

\section{qRT-PCR tissue sampling}

We collected $A$. majus tissue (Fig. 2 and Additional file 5: Table S1) whose developmental stages were determined from a published developmental series [68] or by us. We did not sample organ primordia, because gene expression is known in those stages [20, 21, 24, 26]. We collected Linaria vulgaris and Anarrhinum bellidifolium tissue from developmental stages comparable to $A$. majus. We collected S. lycopersicum tissues (Additional file 5: Table S2) based on published developmental series $[81,82]$. Dorsal and ventral positions were determined relative to the main axis-we dissected flowers with the awareness that $S$. lycopersicum flowers are partly rotated relative to the main axis [83], the carpels are oblique relative to the median plane of the flower $[84,85]$, and that the inflorescences are sympodial [86]. It can be difficult to determine what developmental stages are equivalent between $S$. lycopersicum and A. majus for two reasons. First, because a detailed atlas of $A$. majus fruit development is not available (unlike for $S$. lycopersicum, which are prized for their fruits). In addition, second, because fruits of A. majus are capsules-they undergo a process of drying and death-unlike the fleshy fruits of $S$. lycopersicum. However, the peaks of expression patterns we detect are at or around anthesis. We consider these stages (at/around anthesis) to be equivalent between fruits of $S$. lycopersicum and $A$. majus. This is also apparent morphologically. For example, neither of the fruits undergo their characteristic, rapid enlargement in these stages, and do not abscise their styles-all of which happen at later stages. Given these morphological similarities and the fact that Solanales and Lamiales are close relatives, we consider carpels at or around anthesis to be developmentally equivalent between $S$. lycopersicum and $A$. majus, and hence, justified for comparative analysis.

\section{Identifying homologs}

Gene sources are listed in Additional file 5: Table S3. We isolated RAD orthologs from L. vulgaris and A. bellidifolium by PCR (Bullseye Taq DNA polymerase, Midwest Scientific, St. Louis, MO, USA) using degenerate primers [31]. We generated the following phylogenies to identify the relationship among $R A D, D I V$, and DRIF homologs. First, a tree of $R A D$ and $D I V$ genes in Lamiales, Solanales, and Gentianales (phylogeny in Additional file 1: Fig. S1, alignment and command block in Additional file 2, unedited coding sequences in Additional file 4). Second, a tree of DRIF genes in monocots and eudicots (phylogeny in Additional file 1: Fig. S3, alignment and command block in Additional file 6, unedited coding sequences in Additional file 7). Third, a tree of $D I V$ genes in angiosperms (phylogeny in Additional file 1: Fig. S4, alignment and command block in Additional file 8, unedited coding sequences in Additional file 9). Homologs were translationally aligned using MAFFT [87]. Phylogeny was estimated using MrBayes 3.2.6 [88] available at CIPRES [89www.phylo.org]. The homology among A. majus, $S$. lycopersicum, Vitis vinifera, and Oryza sativa genes is listed in Table 2.

\section{Quantitative RT-PCR}

We extracted total RNA from three biological replicates of each tissue (five biological replicates for carpel tissue in Fig. 5c) type using RNeasy plant minikit (Qiagen, Germantown, MD, USA) or TRI Reagent (Thermo Fisher Scientific, Waltham, MA, USA), followed by DNase treatment (TURBO DNase, Thermo Fisher Scientific), and cDNA synthesis (iScript cDNA Synthesis Kit, Bio-Rad, Hercules, CA, USA). We performed qRT-PCR with three 
technical replicates from each biological replicate in a StepOnePlusTM Real-Time PCR System (Thermo Fisher Scientific) using SYBR Select Master Mix (Thermo Fisher Scientific, for $A m C Y C, A m D I C H, A m R A D, A m D I V$, $A m D R I F 1$, and AmDRIF2), Bullseye EvaGreen qPCR Mastermix (Midwest Scientific, for AmDIV-like1, and all S. lycopersicum genes), and PowerUp SYBR Green Master Mix (Thermo Fisher Scientific, for $A b R A D, L v R A D$, and AmRADlike9). We normalized expression of target genes in A. majus against AmUBIQUITIN5 (AmUBQ5), or its homologs in $A$. bellidifolium and L. vulgaris [43, previously used by 90]. We sequenced the $A m R A D$ qRT-PCR product for stage-14 carpels to confirm that the primers had amplified the correct gene. We normalized expression of target genes in S. lycopersicum against Elongation factor 1-alpha (SlEF1a) [91]. We determined primer efficiencies using DART [92] and analyzed expression employing the $\Delta \Delta \mathrm{Ct}$ method $[93,94]$. Primers are listed in Additional file 5: Table S4.

\section{Virus-induced gene silencing}

Knocking out SlRADlike4 (SlFSM1) function is lethal [41]. We suspected that knocking out any putative transcriptional upregulator of SlRADlike4 could similarly kill all transformants by terminating SIRADlike4 transcription. Therefore, instead of strongly knocking out the expression of the putative upstream regulator by stable transformation, we employed VIGS that downregulates target genes partially, transiently, and in mosaics. We used the pTRV1/2 system to downregulate SITCP26 [9597]. We acquired unmodified $\mathrm{pTRV} 1 / 2$ vectors from The Arabidopsis Resource Center (abrc.osu.edu), amplified a 416 bp fragment of the SITCP26 cDNA and cloned it into pTRV2 using NEBuilder HiFi DNA Assembly Master Mix (NEB). The insert encompasses coding and noncoding regions near the $3^{\prime}$ end of the transcript and can target both transcripts variants of SlTCP26 (HM921069.1 and XM_010319513.2). We used Agrobacterium tumefaciens GV3101 to introduce the pTRV1/2 into tomato seedlings [as described in 95]. As a control, we infiltrated some plants with the empty pTRV2 vector (without the insert) along with the pTRV1. We sampled whole flowers at anthesis (stage-20) to test for downregulation (using extraction and qRT-PCR methods described above). Six pTRV2-insert flowers and eight control flowers (from different plants) were used for testing downregulation of SITCP26 and SlRADlike4. We compared the mean expression of these genes in the control and experimental sets by $T$ test. In addition, we performed VIGS on $S$. lycopersicum PHYTOENE DESATURASE (SIPDS) in a parallel experiment to visually estimate the efficiency of downregulation (data not shown). The pTRV2-SlPDS construct targeted the same region of the native SIPDS transcript as in a previously published work [95].

\section{Putative CYC binding site ancestral state reconstruction}

We identified the orthologs of $A m R A D$ (Additional file 1: Fig. S1) and downloaded 3000 bp upstream of their translational start sites (Additional file 3). We selected species that are early-, mid-, and late-diverging within orders Lamiales and Solanales, and a species from the order Gentianales (Lamiales: Olea europaea, Dorcoceras hygrometricum, Antirrhinum majus, Sesamum indicum; Solanales: Ipomoea nil, Ipomoea lacunosa, Nicotiana benthamiana, Solanum lycopersicum; Gentianales: Galium porrigens var. tenue) [98]. RADIALIS genes are short, conserved, and have rapidly diversified in Lamiales + Solanales, making it difficult to finely resolve their relationships [phylogeny in 36, phylogeny in 43, phylogeny and interpretation in 51]. In the 3000 bp upstream region, we searched for the consensus TCP-binding site $5^{\prime}-$ GGNCCC-3 ${ }^{\prime}[35,52,53]$. It was not possible to determine homology among the predicted consensus TCPbinding sites across species through alignment, because the sites are only six base pairs and the flanking regions are divergent (as expected from fast-evolving, non-coding sequence). Therefore, we estimated the ancestral state by scoring our tree of $R A D$-orthologs (Additional file 1: Fig. S1) for the number of predicted TCP-binding sites in the 3000 bp region (irrespective of location). We scored for three states: no, one, two-or-more predicted TCP-binding sites. Having two or more such sites is likely functional, because $A m R A D$ [under the control of $A m C Y C$, 52] and AtDWARF4 [under the control of $A m C Y C$ ortholog in Arabidopsis, AtTCP1, 56] each have two such sites in their upstream region. We performed parsimony-based ancestral state reconstruction in Mesquite 3.61 [99].

\section{Identifying expression of $C Y C, R A D, D I V$, and DRIF genes from expression atlas}

We acquired expression data for these genes from Vitis vinifera and Oryza sativa. These two species are located outside Lamiales + Solanales, and hence can serve as outgroups. We acquired expression data from the publicly available expression maps at bar.utoronto.ca. This website incorporates material from previously published sources for V. vinifera [100] and O. sativa [101].

\section{Supplementary Information}

The online version contains supplementary material available at https://doi. org/10.1186/s13227-021-00187-w. 
Additional file 1: Fig. S1. Bayesian phylogeny of RAD and DIV genes from Lamiales, Solanales, and Gentianales. The tree was rooted at the mid-point. Posterior probabilities presented at nodes. Names of genes studied with quantitative PCR in larger font. Fig. S2. Dry fruits of Antirrhinum majus. (a). Wildtype in lateral view. (b). Amcycloidea in lateral view. (c). Wildtype in top view. (d). Amcycloidea in top view. Left side is dorsal in (a) and (b). Top is dorsal in (c) and (d). The dorsal locule acquires a ventral identity in the Amcycloidea mutant. Fig. S3. Bayesian phylogeny of DRIF genes in monocots and eudicots. Posterior probabilities presented at nodes. The tree was rooted at the mid-point. Genes with known DIV-DRIF interaction in larger font. Fig. S4. Bayesian phylogeny of DIV genes in angiosperms. Posterior probabilities presented at nodes. The tree was rooted at the mid-point.

Additional file 2: Alignment and command block for Bayesian phylogenetic analysis of RAD and DIV genes used in Additional file 1: Fig. S1.

Additional file 3: Up to 3000 bp upstream of translational start sites of AmRAD orthologs.

Additional file 4: Unedited coding sequences of RAD and DIV genes used in Additional file 1: Fig. S1.

Additional file 5: Table S1. Antirrhinum majus tissue collected for qRT-PCR. Table S2. Solanum lycopersicum tissue collected for qRT-PCR. Table S3. Source of genes used in this study. Table S4. PCR primers. Table S5. Predicted TCP-binding sites within the first 3000 bp immediately upstream of AmRAD orthologs.

Additional file 6: Alignment and command block for Bayesian phylogenetic analysis of DRIF genes used in Additional file 1: Fig. S3.

Additional file 7: Unedited coding sequences of DRIF genes used in Additional file 1 Fig. S3.

Additional file 8: Alignment and command block for Bayesian phylogenetic analysis of DIV genes in angiosperms used in Additional file 1: Fig. S4.

Additional file 9: Unedited coding sequences of DIV genes in angiosperms used in Additional file 1: Fig. S4.

Additional file 10: Figs. S1-S12. Expression the orthologs of AmCYC, AmRAD, AmDIV, AmDRIF1/2, SIMYBI (SIDIVlike5), and SIFSB1 (SIDRIF5) in Vitis vinifera. Images are from bar.utoronto.ca. Some genes are represented by multiple transcripts.

Additional file 11: Figs. S1-S14. Expression the orthologs of AmCYC , AmRAD, AmDIV, AmDRIF1/2, SIMYBI (SIDIVlike5), and SIFSB1 (SIDRIF5) in Oryza sativa. Images are from bar.utoronto.ca. Expression data for one of the AmRAD orthologs Os05g50350 was not available.

\section{Acknowledgements}

The authors thank Katie Sadler, Greenhouse manager, University of Kansas, for help with maintaining plant populations.

\section{Authors' contributions}

LH co-conceived of this project, oversaw analyses, collected VIGS flowers, determined the expression of AbRAD, LVRAD, and AmRADlike9, and contributed to writing the manuscript. AS co-conceived of this project, carried out all other experiments and analyses, and contributed to writing the manuscript. All authors read and approved the final manuscript.

\section{Funding}

This research was supported by The Botanical Society of America (Graduate Student Research Award, Genetics Section Graduate Student Travel Award, Developmental and Structural Section Student Travel Award), and both the General Research Fund and the Benjamin D. Hall, PhD \& Margaret B. Hall Fund through the College of Liberal Arts and Sciences Research Excellence Initiative at the University of Kansas.

\section{Availability of data and materials}

The data sets supporting the conclusions of this article are included within the article (and its Additional files). RADIALIS gene sequences identified in this study are available in GenBank (https://www.ncbi.nlm.nih.gov/genbank/) under accession numbers MW464170 and MW464171.

\section{Declarations}

Ethics approval and consent to participate

Not applicable.

\section{Consent for publication}

Not applicable.

\section{Competing interests}

The authors declare that they have no competing interests.

\section{Author details}

${ }^{1}$ Department of Ecology and Evolutionary Biology, University of Kansas, 1200 Sunnyside Avenue, Lawrence, KS 66045, USA. ${ }^{2}$ Present Address: St. Albert Hall, 8000 Utopia Pkwy, Room 257, Queens, NY 11439, USA.

Received: 7 August 2021 Accepted: 18 December 2021

Published online: 29 January 2022

\section{References}

1. Bharathan $G$, Sinha NR. The regulation of compound leaf development. Plant Physiol. 2001;127:1533-8.

2. Hay A, Tsiantis M. KNOX genes: versatile regulators of plant development and diversity. Development. 2010;137:3153-65.

3. Monteiro A, Podlaha O. Wings, horns, and butterfly eyespots: how do complex traits evolve? PLoS Biol. 2009;7:e1000037.

4. Shubin N, Tabin C, Carroll S. Deep homology and the origins of evolutionary novelty. Nature. 2009;457:818-23.

5. Nakayama H, Yamaguchi T, Tsukaya H. Acquisition and diversification of cladodes: leaf-like organs in the genus Asparagus. Plant Cell. 2012:24:929-40.

6. Nakayama H, Yamaguchi T, Tsukaya H. Modification and co-option of leaf developmental programs for the acquisition of flat structures in monocots: unifacial leaves in Juncus and cladodes in Asparagus. Front Plant Sci. 2013. https://doi.org/10.3389/fpls.2013.00248.

7. Reyes E, Sauquet H, Nadot S. Perianth symmetry changed at least 199 times in angiosperm evolution. Taxon. 2016:65:945-64.

8. Kampny CM. Pollination and flower diversity in Scrophulariaceae. Bot Rev. 1995;61:350-66.

9. Neal PR, Dafni A, Giurfa M. Floral symmetry and its role in plantpollinator systems: terminology, distribution, and hypotheses. Annu Rev Ecol Syst. 1998;29:345-73.

10. Cocucci $A E$, Anton AM. The grass flower: suggestions on its origin and evolution. Flora. 1988;181:353-62.

11. Yuan Z, Gao S, Xue D-W, Luo D, Li L-T, Ding S-Y, et al. RETARDED PALEA controls palea development and floral zygomorphy in rice. Plant Physiol. 2009;149:235-44.

12. O'Meara BC, Smith SD, Armbruster WS, Harder LD, Hardy CR, Hileman LC, et al. Non-equilibrium dynamics and floral trait interactions shape extant angiosperm diversity. Proc R Soc B Biol Sci. 2016;283:20152304.

13. Sargent RD. Floral symmetry affects speciation rates in angiosperms. Proc R Soc Lond B Biol Sci. 2004;271:603-8.

14. Rabosky DL, McCune AR. Reinventing species selection with molecular phylogenies. Trends Ecol Evol. 2010;25:68-74.

15. Reeves PA, Olmstead RG. Evolution of the TCP gene family in Asteridae: cladistic and network approaches to understanding regulatory gene family diversification and its impact on morphological evolution. Mol Biol Evol. 2003;20:1997-2009.

16. Martín-Trillo M, Cubas P. TCP genes: a family snapshot ten years later. Trends Plant Sci. 2010;15:31-9.

17. Yanhui $C$, Xiaoyuan $Y$, Kun $H$, Meihua L, Jigang L, Zhaofeng $G$, et al. The MYB transcription factor superfamily of Arabidopsis: expression analysis and phylogenetic comparison with the rice MYB family. Plant Mol Biol. 2006:60:107-24.

18. Ambawat S, Sharma P, Yadav NR, Yadav RC. MYB transcription factor genes as regulators for plant responses: an overview. Physiol Mol Biol Plants. 2013;19:307-21. 
19. Parapunova V, Busscher M, Busscher-Lange J, Lammers M, Karlova $R$, Bovy AG, et al. Identification, cloning and characterization of the tomato TCP transcription factor family. BMC Plant Biol. 2014;14:157.

20. Luo D, Carpenter R, Vincent C, Copsey L, Coen E. Origin of floral asymmetry in Antirrhinum. Nature. 1996;383:794-9.

21. Luo D, Carpenter R, Copsey L, Vincent C, Clark J, Coen E. Control of organ asymmetry in flowers of Antirrhinum. Cell. 1999;99:367-76.

22. Gübitz T, Caldwell A, Hudson A. Rapid molecular evolution of CYCLOIDEA-like genes in Antirrhinum and its relatives. Mol Biol Evol. 2003;20:1537-44.

23. Hileman LC, Baum DA. Why do paralogs persist? Molecular evolution of CYCLOIDEA and related floral symmetry genes in Antirrhineae (Veronicaceae). Mol Biol Evol. 2003;20:591-600.

24. Corley SB, Carpenter R, Copsey L, Coen E. Floral asymmetry involves an interplay between TCP and MYB transcription factors in Antirrhinum. Proc Natl Acad Sci U S A. 2005;102:5068-73.

25. Almeida J, Rocheta M, Galego L. Genetic control of flower shape in Antirrhinum majus. Development. 1997;124:1387-92.

26. Galego L, Almeida J. Role of DIVARICATA in the control of dorsoventral asymmetry in Antirrhinum flowers. Genes Dev. 2002;16:880-91.

27. Raimundo J, Sobral R, Bailey P, Azevedo H, Galego L, Almeida J, et al. A subcellular tug of war involving three MYB-like proteins underlies a molecular antagonism in Antirrhinum flower asymmetry. Plant J. 2013;75:527-38.

28. Perez-Rodriguez M, Jaffe FW, Butelli E, Glover BJ, Martin C. Development of three different cell types is associated with the activity of a specific MYB transcription factor in the ventral petal of Antirrhinum majus flowers. Development. 2005;132:359-70.

29. Citerne HL, Möller M, Cronk QCB. Diversity of cycloidea -like genes in Gesneriaceae in relation to floral symmetry. Ann Bot. 2000;86:167-76.

30. Gao Q, Tao J-H, Yan D, Wang Y-Z, Li Z-Y. Expression differentiation of CYC-like floral symmetry genes correlated with their protein sequence divergence in Chirita heterotricha (Gesneriaceae). Dev Genes Evol. 2008;218:341-51.

31. Preston JC, Martinez CC, Hileman LC. Gradual disintegration of the floral symmetry gene network is implicated in the evolution of a wind-pollination syndrome. Proc Natl Acad Sci U S A. 2011;108:2343-8.

32. Preston JC, Barnett LL, Kost MA, Oborny NJ, Hileman LC. Optimization of virus-induced gene silencing to facilitate evo-devo studies in the emerging model species Mimulus guttatus (Phrymaceae). Ann Mo Bot Gard. 2014;99:301-12.

33. Su S, Xiao W, Guo W, Yao X, Xiao J, Ye Z, et al. The CYCLOIDEA-RADIALIS module regulates petal shape and pigmentation, leading to bilateral corolla symmetry in Torenia fournieri (Linderniaceae). New Phytol. 2017;215:1582-93.

34. Yang X, Cui H, Yuan Z-L, Wang Y-Z. Significance of consensus CYCbinding sites found in the promoters of both ChCYC and ChRAD genes in Chirita heterotricha (Gesneriaceae). J Syst Evol. 2010;48:249-56.

35. Yang X, Pang H-B, Liu B-L, Qiu Z-J, Gao Q, Wei L, et al. Evolution of double positive autoregulatory feedback loops in CYCLOIDEA2 clade genes is associated with the origin of floral zygomorphy[W]. Plant Cell. 2012;24:1834-47.

36. Zhong J, Kellogg EA. Stepwise evolution of corolla symmetry in CYCLOIDEA2-like and RADIALIS-like gene expression patterns in Lamiales. Am J Bot. 2015;102:1260-7.

37. Zhong J, Kellogg EA. Duplication and expression of CYC2-like genes in the origin and maintenance of corolla zygomorphy in Lamiales. New Phytol. 2015;205:852-68.

38. Zhou X-R, Wang Y-Z, Smith JF, Chen R. Altered expression patterns of TCP and MYB genes relating to the floral developmental transition from initial zygomorphy to actinomorphy in Bournea (Gesneriaceae). New Phytol. 2008;178:532-43.

39. Stull GW, de Stefano RD, Soltis DE, Soltis PS. Resolving basal lamiid phylogeny and the circumscription of /cacinaceae with a plastome-scale data set. Am J Bot. 2015;102:1794-813.

40. Zhang J, Stevens PF, Zhang W. Evolution of floral zygomorphy in androecium and corolla in Solanaceae. J Syst Evol. 2017;55:581-90.

41. Machemer K, Shaiman O, Salts Y, Shabtai S, Sobolev I, Belausov E, et al. Interplay of MYB factors in differential cell expansion, and consequences for tomato fruit development. Plant J. 2011;68:337-50.
42. Gao A, Zhang J, Zhang W. Evolution of RAD- and DIV-like genes in plants. Int J Mol Sci. 2017;18:1961.

43. Sengupta A, Hileman LC. Novel traits, flower symmetry, and transcriptional autoregulation: new hypotheses from bioinformatic and experimental data. Front Plant Sci. 2018. https://doi.org/10.3389/fpls. 2018.01561

44. Fernandez-Pozo N, Zheng Y, Snyder SI, Nicolas P, Shinozaki Y, Fei Z, et al. The tomato expression atlas. Kelso J, editor. Bioinformatics. 2017:33:2397-8.

45. Raimundo J, Sobral R, Laranjeira S, Costa MMR. Successive domain rearrangements underlie the evolution of a regulatory module controlled by a small interfering peptide. Mol Biol Evol. 2018;35:2873-85.

46. Huchard E, Martinez M, Alout H, Douzery EJP, Lutfalla G, Berthomieu A, et al. Acetylcholinesterase genes within the Diptera: takeover and loss in true flies. Proc R Soc B Biol Sci. 2006;273:2595-604.

47. Li M, Zhang D, Gao Q, Luo Y, Zhang H, Ma B, et al. Genome structure and evolution of Antirrhinum majus L. Nat Plants. 2019;5:174.

48. Sengupta A, Hileman LC. Evolution of novel genetic programs: insights from flower and fruit development. University of Kansas; 2019 (cited 2021 Sep 28). https://kuscholarworks.ku.edu/handle/1808/29628.

49. Lönnig W-E, Stüber K, Saedler H, H. Kim J. Biodiversity and Dollo's Law: to what extent can the phenotypic differences between Misopates orontium and Antirrhinum majus be bridged by mutagenesis? Bioremediation Biodivers Bioavailab V1 1-30 2007. 2018;

50. Broholm SK, Tähtiharju S, Laitinen RAE, Albert VA, Teeri TH, Elomaa P. A TCP domain transcription factor controls flower type specification along the radial axis of the Gerbera (Asteraceae) inflorescence. Proc Natl Acad Sci. 2008;105:9117-22

51. Zhong J, Preston JC, Hileman LC, Kellogg EA. Repeated and diverse losses of corolla bilateral symmetry in the Lamiaceae. Ann Bot. 2017;119:1211.

52. Costa MMR, Fox S, Hanna Al, Baxter C, Coen E. Evolution of regulatory interactions controlling floral asymmetry. Development. 2005;132:5093-101.

53. Kosugi $S$, Ohashi Y. DNA binding and dimerization specificity and potential targets for the TCP protein family. Plant J. 2002;30:337-48.

54. Cubas P. Floral zygomorphy, the recurring evolution of a successful trait. BioEssays. 2004:26:1175-84.

55. Koyama T, Sato F, Ohme-Takagi M. A role of TCP1 in the longitudinal elongation of leaves in Arabidopsis. Biosci Biotechnol Biochem. 2010;74:2145-7

56. Gao Y, Zhang D, Li J. TCP1 modulates DWF4 expression via directly interacting with the GGNCCC motifs in the promoter region of DWF4 in Arabidopsis thaliana. J Genet Genomics. 2015;42:383-92.

57. Hileman LC. Trends in flower symmetry evolution revealed through phylogenetic and developmental genetic advances. Philos Trans R Soc B Biol Sci. 2014;369:20130348.

58. Howarth DG, Donoghue MJ. Duplications in CYC -like genes from Dipsacales correlate with floral form. Int J Plant Sci. 2005;166:357-70.

59. Howarth DG, Donoghue MJ. Duplications and expression of DIVARICATA -like genes in Dipsacales. Mol Biol Evol. 2009;26:1245-58.

60. Boyden GS, Donoghue MJ, Howarth DG. Duplications and expression of RADIALIS-like genes in Dipsacales. Int J Plant Sci. 2012;173:971-83. https://doi.org/10.1086/667626.

61. Berger BA, Ricigliano VA, Savriama Y, Lim A, Thompson V, Howarth DG. Geometric morphometrics reveals shifts in flower shape symmetry and size following gene knockdown of CYCLOIDEA and ANTHOCYANIDIN SYNTHASE. BMC Plant Biol. 2017;17:205.

62. Horn S, Pabón-Mora N, TheußVS, Busch A, Zachgo S. Analysis of the CYC/TB1 class of TCP transcription factors in basal angiosperms and magnoliids. Plant J. 2015;81:559-71.

63. Madrigal Y, Alzate JF, González F, Pabón-Mora N. Evolution of RADIALIS and DIVARICATA gene lineages in flowering plants with an expanded sampling in non-core eudicots. Am J Bot. 2019;106:334-51.

64. Madrigal Y, Alzate JF, Pabón-Mora N. Evolution and expression patterns of TCP genes in Asparagales. Front Plant Sci. 2017. https://doi.org/10. 3389/fpls.2017.00009

65. Valoroso MC, Sobral R, Saccone G, Salvemini M, Costa MMR, Aceto S. Evolutionary conservation of the orchid MYB transcription factors DIV, RAD, and DRIF. Front Plant Sci. 2019. https://doi.org/10.3389/fpls.2019. 01359 . 
66. Cubas P, Coen E, Zapater JMM. Ancient asymmetries in the evolution of flowers. Curr Biol. 2001;11:1050-2.

67. Busch A, Horn S, Mühlhausen A, Mummenhoff K, Zachgo S. corolla monosymmetry: evolution of a morphological novelty in the Brassicaceae family. Mol Biol Evol. 2012;29:1241-54.

68. Vincent CA, Coen ES. A temporal and morphological framework for flower development in Antirrhinum majus. Can J Bot. 2004:82:681-90.

69. Zhao Y, Pfannebecker K, Dommes AB, Hidalgo O, Becker A, Elomaa P. Evolutionary diversification of CYC/TB1-like TCP homologs and their recruitment for the control of branching and floral morphology in Papaveraceae (basal eudicots). New Phytol. 2018;220:317-31.

70. Baxter CEL, Costa MMR, Coen ES. Diversification and co-option of RADlike genes in the evolution of floral asymmetry. Plant J. 2007:52:105-13.

71. Valoroso MC, De Paolo S, lazzetti G, Aceto S. Transcriptome-wide identification and expression analysis of DIVARICATA- and RADIALISLike genes of the mediterranean orchid Orchis italica. Genome Biol Evol. 2017:9:1418-31

72. True JR, Carroll SB. Gene co-option in physiological and morphological evolution. Annu Rev Cell Dev Biol. 2002;18:53-80.

73. Stern DL. The genetic causes of convergent evolution. Nat Rev Genet. 2013;14:751-64

74. Spitz F, Gonzalez F, Peichel C, Vogt TF, Duboule D, Zákány J. Large scale transgenic and cluster deletion analysis of the HoxD complex separate an ancestral regulatory module from evolutionary innovations. Genes Dev. 2001;15:2209-14

75. Bharathan G, Goliber TE, Moore C, Kessler S, Pham T, Sinha NR. Homologies in leaf form inferred from KNOXI gene expression during development. Science. 2002;296:1858-60.

76. Citerne HL, Luo D, Pennington RT, Coen E, Cronk QCB. A phylogenomic investigation of CYCLOIDEA-Like TCP genes in the Leguminosae. Plant Physiol. 2003;131:1042-53.

77. Busch A, Zachgo S. Control of corolla monosymmetry in the Brassicaceae Iberis amara. Proc Natl Acad Sci U S A. 2007:104:16714-9.

78. Werner T, Koshikawa S, Williams TM, Carroll SB. Generation of a novel wing colour pattern by the Wingless morphogen. Nature. 2010:464:1143-8.

79. Sordino P, van der Hoeven F, Duboule D. Hox gene expression in teleost fins and the origin of vertebrate digits. Nature. 1995;375:678-81.

80. Brakefield PM, Gates J, Keys D, Kesbeke F, Wijngaarden PJ, Montelro A, et al. Development, plasticity and evolution of butterfly eyespot patterns. Nature. 1996;384:236-42.

81. Gillaspy G, Ben-David H, Gruissem W. Fruits: a developmental perspective. Plant Cell. 1993;5:1439-51.

82. Brukhin V, Hernould M, Gonzalez N, Chevalier C, Mouras A. Flower development schedule in tomato Lycopersicon esculentum cv. sweet cherry. Sex Plant Reprod. 2003;15:311-20.

83. Knapp S. Floral diversity and evolution in Solanaceae. In: Cronk QCB Bateman RM, Hawkins JA, editors. Dev Genet Plant Evol. Boca Raton: CRC Press; 2004

84. Craene LPRD. Floral diagrams: an aid to understanding flower morphology and evolution. Cambridge: Cambridge University Press; 2010

85. Murray MA. Carpellary and placental structure in the Solanaceae. Bot Gaz. 1945:107:243-60.

86. Hake S. Inflorescence architecture: the transition from branches to flowers. Curr Biol. 2008:18:R1106-8.

87. Katoh K, Misawa K, Kuma K, Miyata T. MAFFT: a novel method for rapid multiple sequence alignment based on fast Fourier transform. Nucleic Acids Res. 2002;30:3059-66.

88. Ronquist F, Teslenko M, van der Mark P, Ayres DL, Darling A, Höhna S, et al. MrBayes 3.2: efficient bayesian phylogenetic inference and model choice across a large model space. Syst Biol. 2012;61:539-42.

89. Miller MA, Pfeiffer W, Schwartz T. Creating the CIPRES Science Gateway for inference of large phylogenetic trees. 2010 Gatew Comput Environ Workshop GCE. 2010. p. 1-8.

90. Preston JC, Hileman LC. SQUAMOSA-PROMOTER BINDING PROTEIN 1 initiates flowering in Antirrhinum majus through the activation of meristem identity genes. Plant J Cell Mol Biol. 2010;62:704-12.

91. Expósito-Rodríguez M, Borges AA, Borges-Pérez A, Pérez JA. Selection of internal control genes for quantitative real-time RT-PCR studies during tomato development process. BMC Plant Biol. 2008:8:131
92. Peirson SN, Butler JN, Foster RG. Experimental validation of novel and conventional approaches to quantitative real-time PCR data analysis. Nucleic Acids Res. 2003:31:e73-e73.

93. Pfaff MW. A new mathematical model for relative quantification in realtime RT-PCR. Nucleic Acids Res. 2001;29:e45.

94. Pfaff MW. Relative quantification. In: Dorak MT, editor. Real-time PCR. 1st ed. New York: Taylor \& Francis; 2007. p. 63-82.

95. Dinesh-Kumar SP, Anandalakshmi R, Marathe R, Schiff M, Liu Y. Virusinduced gene silencing. In: Grotewold E, editor. Plant Functional Genomics. 2003 (cited 2014 Nov 22). p. 287-93. https://doi.org/10. 1385/1-59259-413-1\%3A287

96. Liu Y, Schiff M, Dinesh-Kumar SP. Virus-induced gene silencing in tomato. Plant J. 2002;31:777-86.

97. Padmanabhan M, Dinesh-Kumar SP. Virus-induced gene silencing as a tool for delivery of dsRNA into plants. Cold Spring Harb Protoc. 2009; 2009:pdb.prot5139.

98. Refulio-Rodriguez NF, Olmstead RG. Phylogeny of Lamiidae. Am J Bot. 2014:101:287-99.

99. Maddison WP, Maddison DR. Mesquite: a modular system for evolutionary analysis. 2018. http://www.mesquiteproject.org.

100. Fasoli M, Dal Santo S, Zenoni S, Tornielli GB, Farina L, Zamboni A, et al. The grapevine expression atlas reveals a deep transcriptome shift driving the entire plant into a maturation program. Plant Cell. 2012:24:3489-505.

101. Jain M, Nijhawan A, Arora R, Agarwal P, Ray S, Sharma P, et al. F-Box Proteins in Rice. Genome-wide analysis, classification, temporal and spatial gene expression during panicle and seed development, and regulation by light and abiotic stress. Plant Physiol. 2007;143:1467-83.

102. Sengupta A, Hileman LC. Novel traits, flower symmetry, and transcriptional autoregulation: new hypotheses from bioinformatic and experimental data. Front Plant Sci. 2018:9:1561.

103. Ogutcen E, Vamosi JC. A phylogenetic study of the tribe Antirrhineae: genome duplications and long-distance dispersals from the Old World to the New World. Am J Bot. 2016;103:1071-81.

\section{Publisher's Note}

Springer Nature remains neutral with regard to jurisdictional claims in published maps and institutional affiliations.

Ready to submit your research? Choose BMC and benefit from

- fast, convenient online submission

- thorough peer review by experienced researchers in your field

- rapid publication on acceptance

- support for research data, including large and complex data types

- gold Open Access which fosters wider collaboration and increased citations

- maximum visibility for your research: over 100M website views per year

At BMC, research is always in progress.

Learn more biomedcentral.com/submissions 